\title{
Understanding the chapatti making attributes of the Indian wheats - II: The rheological basis
}

\author{
Satish Kumar* \\ Virinder Singh Sohu \\ Punjab Agricultural University, Ludhiana - 141004 (Punjab), India \\ Satish Kumar Gupta \\ Punjab Agricultural University, Ludhiana - 141004 (Punjab), India \\ Rajinder Pal Singh \\ Punjab Agricultural University, Ludhiana - 141004 (Punjab), India \\ Navtej Singh Bains \\ Punjab Agricultural University, Ludhiana - 141004 (Punjab), India \\ *Corresponding author. E-mail: kumarsatish227@gmail.com
}

ICAR - Indian Institute of Wheat and Barley Research, Karnal - 132001 (Haryana), India

\begin{abstract}
The concept of good chapati varies from individual to individual and depends mainly on the rheological properties of the dough used to prepare the chapaties. The research project was largely built around two type of plant meterials, the tall traditional cultivars of the pre-dwarfing era, and three backcross recombinant populations $\left(\mathrm{BC}_{1} \mathrm{~F}_{5}\right.$ generation) $\mathrm{C}$ 273/PBW 343//PBW 343 (70 lines), C 306/PBW 534//PBW 534 (70 lines) and C 518/ PBW 343//PBW 343 (80 lines). Association of traits studied with chapati score in set of cultivars and genetic stocks Starch pasting characteristics showed mild negative correlation with chapati quality, which is again contrasting, to the requirements of bread making. The correlations were not consistent over years possibly due to environmental factor (temperature, rainfall, fertilizer and irrigations etc.) and due to change in the constitution of the set. Similarly mixographic traits showed negative association chapati making quality. The correlations which prevail in the populations carry much greater weight as these have persisted over several rounds of recombination and are likely to reflect under lying causes of superior chapati quality. As various components of chapati quality would be disassembled, the relative levels of correlations for individual traits would be uncovered. Among the starch pasting characteristics, final viscosity and setback were consistently negatively associated with the chapati making quality. In case of the mixographic traits, mixing tolerance index is negatively associated whereas rate of dough development has consistent positive correlation with chapati quality.
\end{abstract}

Keywords: Chapati making quality, Mixograph, Rheological properties, Starch pasting, Wheat

\section{INTRODUCTION}

Wheat is the leading cereal grain produced, consumed and traded in the world. It is the second most important crop after rice in India and grown on around 30 mha area. In India, the annual wheat production was 98.37 million tonnes (201617) whereas global wheat production was estimated at 735.3 million tonnes during 2015-16, (Anonymous, 2016). Since there are large differences in grain quality requirements for major baked food types such as bread, pastries, noodles, and cookies etc., the grain quality required to produce flat bread, like Indian chapati is different from that required to make a pan type bread. The technological interventions for processing of wheat floor depend mainly on the reheological properties

\section{Article Info}

DOI:10.31018/jans.v10i2.1773

Received: March 1, 2018

Revised: March 26, 2018

Accepted: May 9, 2018

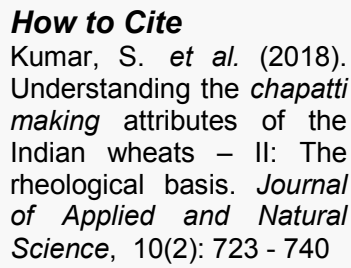

Kumar, S. et al. (2018).

Understanding the chapatti making attributes of the Indian wheats - II: The of Applied and Natural Science, 10(2): 723 - 740 of the dough used to prepare the chapaties.

Sinha and Singh (1974) studied the rheological characteristics of 25 varieties from the four wheat growing states on the farinograph and categorized those for different purposes. Studies on the rheological aspects of improved wheat varieties were conducted by Austin and Hanslas (1983). The authors observed that for chapati making medium strong dough is the ideal choice. Rao et al (1989) studied the effect of damaged starch on the functional quality characteristics of whole meal flour used for chapati-making. Damaged starch in the flour was positively correlated to the diastatic activity and flour water absorption.

Saxena et al (1997) tried to correlate the physicochemical and rheological characteristics of wheat flour with the tandoori roti quality, using eight com- 
mercial wheat cultivars (PBW 154, PBW 175, PBW 229, PBW 138, WL 1562, CPAN 3004, GW 180 and $\mathrm{K} 8804$ ) grown at one location. Varieties with high water absorption capacity gave roties with better quality. Rheological properties were improved upon adding isolated arabinoxylans of good chapati making varieties to flours. Interestingly, addition of isolated arabinoxylans of good chapati making varieties to poor chapati making varieties had significantly improved the chapati quality (Das et al, 2006; Hemalatha et al, 2006). Sensory studies showed that chapatis prepared from flour added with arabinoxylans of good chapati varieties had soft texture and high overall quality scores. (Hemalatha et al 2013) reported that due to their high water binding capacity water soluble arabinoxylans are known to play an important role in rheological properties of dough, retrogradation of starch and breadmaking quality. Addition of water soluble arabinoxylans to refined wheat flour significantly increased the farinograph water absorption and dough development time and also increased bread quality parameters like loaf volume, crumb structure and de-creased staling characteristics. Sasaki et al (2008) determined visco-elastic properties of wheat flours, starch and gluten-starch mixture with varying amylose content and reported that the amylase content strongly affected rheological properties of flour gels. Seib (2000) reported that the elastic response of starch gels increased with increase in amylose content in the continuous phase, the volume fraction of swollen granules, rigidity of dispersed granules and adhesion between dispersed and continuous phases. Wheat cultivars with high-amylose have been used to increase resistant starch in breads (Hung et al 2005) and to improve the texture of noodles (Morita et al 2003). In addition, Blazek and Copeland (2008) and Singh et al (2011) reported that non-starch constituents, e.g. proteins, lipids and non-starch polysaccharides also influence rheological/viscoelastic properties of wheat flours.

The present study was taken up with the aim to understand the reheological characteristics of wheat dough and their correlation with chapatimaking properties. Genotypes known to have good chapati-making characteristics are known to be grown under different production conditions. Since the growing environment plays an important role for the expression of multigenic traits such as chapati quality, studies in one environment with the genotypes known to have good quality will be helpful in understanding this trait and its association with end use quality.

\section{MATERIALS AND METHODS}

Plant material used in study: The research project was largely built around the tall traditional cultivars of the pre-dwarfing era, which were known to excel for chapati quality. These included C 306, C 518 and C 273. The few cultivars that had emanated from crosses of these superior chapati quality wheats with dwarf wheats formed another important component of this set and included WG 357, PBW 175, PBW 154, PBW 226. Lok 1 and others as mentioned in the table $2 \& 3$. All the plant material was sown in a randomized complete block design in three replications with a plot size of $2 \mathrm{~m}$ length and four rows per plot. To represent the second set of materials, three backcross recombinant populations ( $\mathrm{BC}_{1} \mathrm{~F}_{5}$ generation) derived from C 273/PBW 343//PBW 343 (70 lines), C 306/PBW 534//PBW 534 (70 lines) and C 518/PBW 343//PBW 343 (80 lines) were studied (details discussed in part I).

\section{Observations recorded:}

Rheological properties based on mixographic studies: The mixograph was operated using AACC (1990) approved method with $35 \mathrm{~g}$ flour (14\% moisture basis) The mixer was run for exactly 7 min using 63 percent absorption. The spring tension was kept at No.9. The curves were interpreted for different parameters as follows: -

Mixing time: The Time taken by the curve from the start of the mixing to reach the peak consistency

Dough Strength: It is measured as the height of the curve in $\mathrm{cm}$. measured from the center of the curve at peak to the base line.

Dough development area $\left(\mathbf{c m}^{2}\right)$ : It is the area under the curve measured from the center of the curve upto the base line, from start of mixing upto the peak is reached. It was measured using a planimeter.

Area under curve: It is taken from the center of recorded curve to base line, from beginning of mixing until. The mixing of 7 mins has elapsed. It was measured using "Planimeter" and is termed as the baking strength.

Rate of dough development: It is the measure of angle formed by the line through the center of the ascending curve with the one drawn through the center of the curve at the peak and parallel to the base line.

Rate of dough weakening: It is the angle formed by the line through the centre of the descending curve with one as above.

Mixing tolerance: It is the angle enclosed by the lines drawn through the ascending and descending curve at peak point.

Starch pasting characteristics: The starch pasting characteristics were estimated with Starch Master using the following procedure: Allow the instrument to warm up for 30 min prior to the experiment. Weigh 4.0 (14\% moisture basis) of wholemeal in a consister and add $25.0 \mathrm{ml}$ distilled water into the consister. Place the paddle into the consister and vigorously jog the blade through the sample up and down 10 times or until it mixes 
uniformly. Insert the consister into the preadjusted instrument using the standard profile given below (Table 1):

The measurement cycle was initiated by depressing the motor tower of the instrument. The canister on completion of test was removed and discarded. The gelatinization temperature, peak viscosity, breaks down value, hold viscosity, setback value and final viscosity from the instrument were recorded.

Chapati-making characteristics: For baking chapaties the method used in the quality laboratory Department of Plant Breeding and Genetics was employed (Kumar et al, 2018). The chapati score was calculated using the parameters Dough stickiness (5), Puffing of chapatti (5), Texture of chapati (5), Color of chapati (5), Taste of chapati (5), Flavor of chapati (5) and Texture of chapati after 2 hrs (5). The total score was finally calculated out of a maximum of ten.

\section{Data analysis}

Analysis of variance: The material had been planted in a randomized complete block design. The analysis of variance for different traits was done as per the following model:

Equation $\mathrm{l}: \quad \mathrm{Y}_{\mathrm{ij}}=\mathrm{m}+\mathrm{t}_{\mathrm{i}}+\mathrm{b}_{\mathrm{j}}+\mathrm{e}_{\mathrm{ij}}$

$Y_{i j}=$ observation obtained from the $i{ }^{\text {th }}$ treatment and j-th block.

$\mathrm{m}=$ general mean

$t_{i}=$ the effect of $i^{\text {th }}{ }^{-}$treatment

$b_{j}=$ the effect of $j_{-}{ }^{\text {th }}$ block

$\mathrm{e}_{\mathrm{ij}}=$ error associated with $\mathrm{i}$-th treatment and $\mathrm{j}$-th block

The analysis of variance based on the above model takes the following form:

Critical Difference (CD) to compare two genotypes was computed as follows:

Equation II:

$$
C D=\sqrt{\frac{2 M S E}{r}} \times t_{a}(r-1)(g-1)
$$

Where, $a=$ level of significance

Correlation coefficients: The correlation coefficient $(r$ ) between two different observations (say $X$ and $Y$ ) was calculated using the following formula: Equation III:

$$
r_{x y}=\frac{\sum\left(x_{i}-\bar{x}\right)\left(y_{i}-\bar{y}\right)}{(n-1) s_{x} s_{y}}
$$

Where: $x$ and $y=$ means of variables

$$
\begin{array}{ll}
\mathrm{S}_{\mathrm{x}} \text { and } \mathrm{s}_{\mathrm{y}} & =\text { standard deviations of } \mathrm{x} \text { and } \mathrm{y} \\
\mathrm{n} & =\text { population size. }
\end{array}
$$$$
\mathrm{n}
$$

Table 1. The profile of the method used for determining the starch pasting characteristics.

\begin{tabular}{lll}
\hline Time & Temp & Values \\
\hline 00:00:00 & Speed & $960 \mathrm{rpm}$ \\
00:00:10 & Speed & $160 \mathrm{rpm}$ \\
00:00:10 & Temp & $50{ }^{\circ} \mathrm{C}$ \\
00:01:00 & Temp & $50^{\circ} \mathrm{C}$ \\
00:04:42 & Temp & $95^{\circ} \mathrm{C}$ \\
00:07:12 & Temp & $95^{\circ} \mathrm{C}$ \\
00:11:00 & Temp & $50^{\circ} \mathrm{C}$ \\
\hline \hline Idle Temperature & & $: 50 \pm 1^{\circ} \mathrm{C}$ \\
End of Test & $: 13 \mathrm{~min}$ \\
Time between readings & $: 4 \mathrm{sec}$ \\
\hline
\end{tabular}

\section{RESULTS AND DISCUSSION}

Genetic variation for Chapati score: Chapati score is a composite trait and is based on dough handling (stickiness of the dough), puffing of chapati, texture, taste, flavour and colour of the chapati. Conventionally, a chapati score above 8 (out of 10) represents excellent chapati quality. Significant genotypic differences were observed for chapati score of the genotypes in both the years (Table $3 a$ and b). The chapati score showed variation between the groups of genotypes, with the tall wheats of pre dwarfing era excelling over other groups. The tall varieties not only established themselves as a distinct group with highest chapati score (Table 4 and 5 ). The genetic stocks, on the other hand again failed to give good chapaties thus emphasizing the fact that good chapati quality resulted from a combination of different component traits and not because of one or two traits. The advanced breeding lines in this season again showed an intermediate chapati score.

Similarly, significant genotypic differences $(5 \%$ level of significance) were observed for chapati score in all the three populations viz: 'A' (C273/ PBW343//PBW343), 'B' (C306/PBW534//PBW534) and ' $C$ ' (C518/PBW343//PBW343) (Table 6a, b and $c$ ). Details of variation in chapati score have already been discussed in the part I.

Genetic variation for mixographic characteristics: The mixograph was initially developed to determine precisely the mixing requirements of dough. But in addition the mixograms are interpreted for other parameters like strength of dough, mixing tolerance and baking strength etc. Ideally a good baking wheat variety should have a shorter mixing time and high dough strength, baking strength and mixing tolerance values. The set of genotypes exhibited highly significant variation for the mixographic characteristics during both sea-

Table 2. Analysis of variance for randomized block design.

\begin{tabular}{lllll}
\hline Source & d. $\mathbf{f}$ & Sum of Squares & Mean sum of squares & F-ratio \\
\hline Replications & $\mathrm{r}-1$ & RSS & MSR & MSR/MSE \\
Treatments & $\mathrm{g}-1$ & GSS & MST & MST/MSE \\
Error & $(\mathrm{r}-1)(\mathrm{g}-1)$ & SSE & MSE & \\
\hline
\end{tabular}

Where, $r=$ no. of replications, $g=$ no. of genotypes 


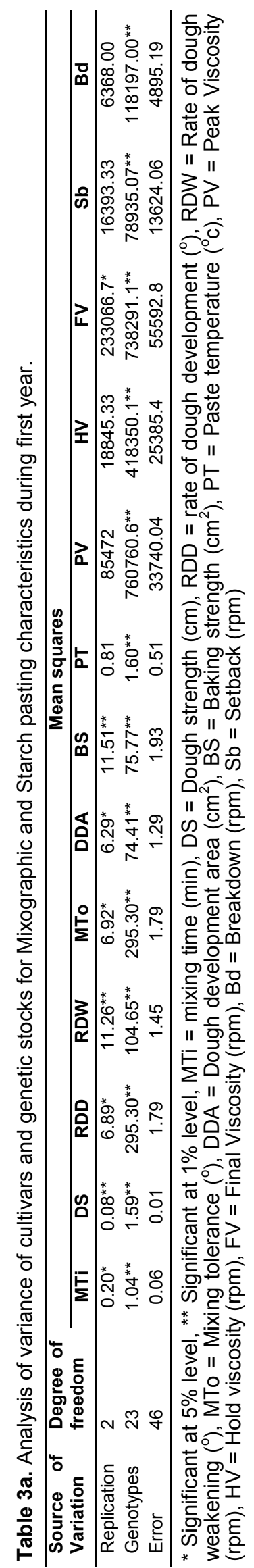

Kumar S. et al. / J. Appl. \& Nat. Sci. 10 (2): 723 - 740 (2018)

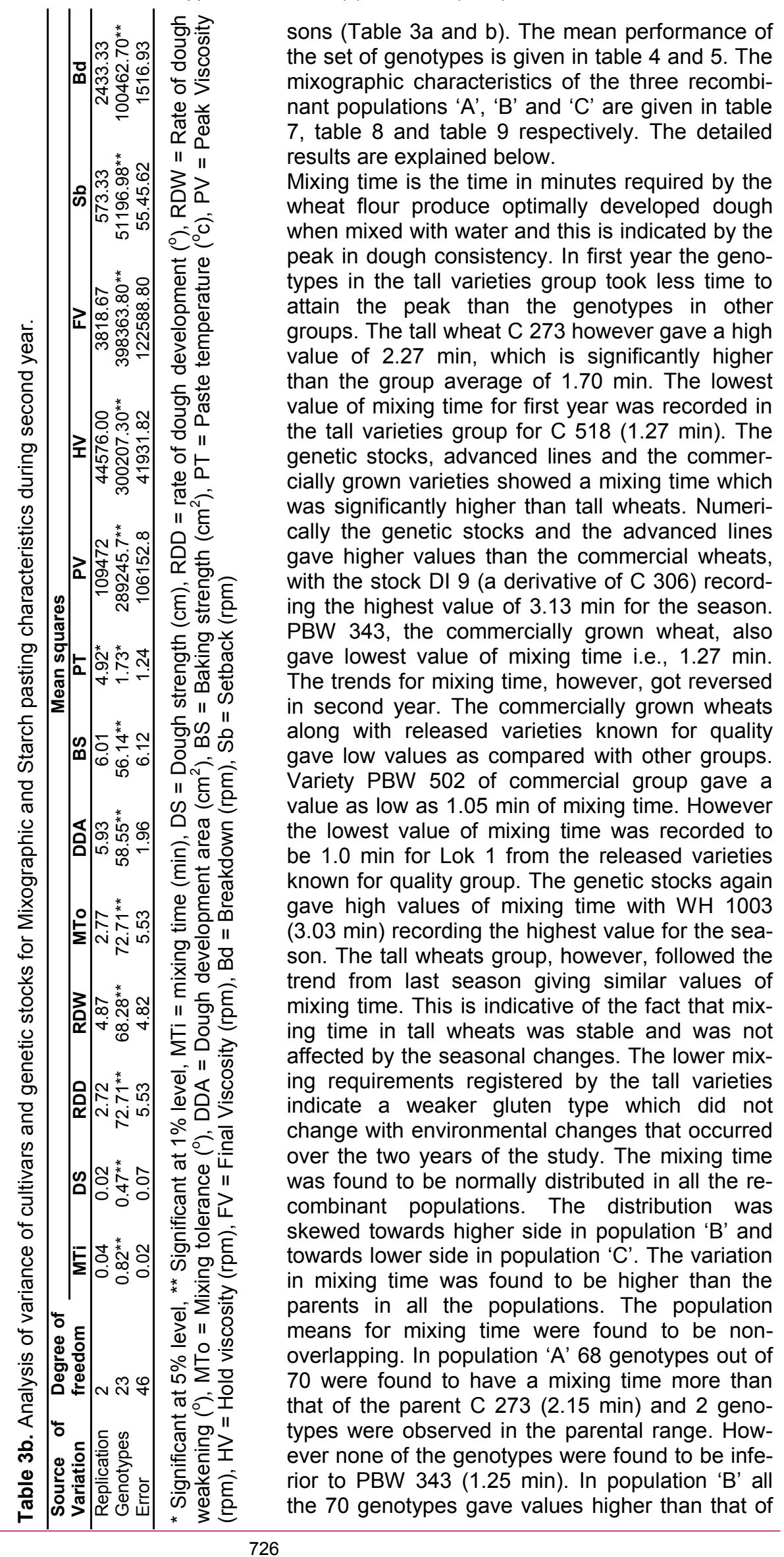


Kumar S. et al. / J. Appl. \& Nat. Sci. 10 (2): 723 - 740 (2018)

Table 4. Mean performance of cultivars and genetic stocks evaluated for mixographic and starch pasting characteristics during first year.

\begin{tabular}{|c|c|c|c|c|c|c|c|c|c|c|c|c|c|c|}
\hline Genotype & MTi & DS & RDD & RDW & MTo & DDA & BS & PT & PV & $\mathrm{HV}$ & $\mathrm{FV}$ & Bd & Sb & CS \\
\hline C 273 & 2.27 & 6.40 & 39.33 & 33.33 & 140.67 & 18.67 & 42.67 & 68.27 & 2575.33 & 1606.33 & 2788.00 & 969.00 & 1181.67 & 7.9 \\
\hline C 306 & 1.67 & 6.33 & 40.67 & 28.00 & 139.33 & 15.00 & 43.33 & 68.47 & 2588.00 & 1679.67 & 3132.00 & 908.33 & 1452.33 & 8.1 \\
\hline C 518 & 1.27 & 6.33 & 46.67 & 27.33 & 133.33 & 9.00 & 39.00 & 68.67 & 2049.67 & 1227.67 & 2414.67 & 822.00 & 1187.00 & 8.0 \\
\hline C 591 & 1.77 & 5.60 & 37.33 & 15.33 & 142.67 & 13.00 & 41.33 & 68.90 & 3021.33 & 1911.67 & 3214.33 & 1109.66 & 1302.66 & 8.0 \\
\hline WG 357 & 1.53 & 7.23 & 50.33 & 34.00 & 129.67 & 13.00 & 48.67 & 68.00 & 2965.00 & 1777.67 & 2858.33 & 1187.33 & 1080.66 & 7.6 \\
\hline PBW 343 & 1.27 & 6.07 & 51.67 & 21.67 & 128.33 & 10.00 & 40.00 & 68.60 & 2866.33 & 1874.33 & 3240.67 & 992.00 & 1366.34 & 7.6 \\
\hline PBW 550 & 2.60 & 6.30 & 26.00 & 18.33 & 154.00 & 21.00 & 49.67 & 67.07 & 3193.00 & 2090.33 & 3375.33 & 1102.67 & 1285.00 & 7.4 \\
\hline PBW 502 & 1.40 & 5.53 & 34.67 & 33.00 & 145.33 & 9.33 & 39.00 & 69.03 & 2434.67 & 1730.67 & 2560.67 & 704.00 & 830.00 & 7.4 \\
\hline PBW 509 & 2.83 & 5.73 & 37.33 & 30.33 & 142.67 & 20.33 & 42.00 & 68.60 & 3208.00 & 1836.67 & 3059.00 & 1371.33 & 1222.33 & 7.6 \\
\hline PBW 554 & 2.10 & 7.03 & 41.67 & 28.33 & 138.33 & 17.33 & 48.00 & 68.33 & 2946.33 & 1720.33 & 2819.67 & 1226.00 & 1099.34 & 7.6 \\
\hline PBW 531 & 1.93 & 6.70 & 39.00 & 32.33 & 141.00 & 16.33 & 49.33 & 67.20 & 2698.00 & 1606.00 & 2553.33 & 1092.00 & 947.33 & 7.6 \\
\hline PBW 534 & 2.19 & 5.83 & 19.67 & 23.67 & 160.33 & 20.67 & 50.33 & 69.90 & 3580.00 & 2528.33 & 4154.00 & 1051.67 & 1625.67 & 7.5 \\
\hline Pusa 5-3 & 1.93 & 6.00 & 35.33 & 26.33 & 144.67 & 14.00 & 41.67 & 68.63 & 2609.33 & 1734.67 & 3131.00 & 874.66 & 1396.33 & 7.2 \\
\hline DI 105 & 1.70 & 5.70 & 46.33 & 18.67 & 133.67 & 11.67 & 44.33 & 69.03 & 2932.33 & 1868.00 & 3252.67 & 1064.33 & 1384.67 & 7.8 \\
\hline DI 9 & 3.13 & 4.97 & 16.67 & 13.33 & 163.33 & 18.00 & 42.00 & 67.63 & 2775.67 & 1585.33 & 3195.00 & 1190.34 & 1609.67 & 7.8 \\
\hline WH 423 & 2.07 & 5.90 & 28.00 & 23.33 & 152.00 & 12.33 & 40.33 & 68.13 & 1609.67 & 919.67 & 1827.67 & 690.00 & 908.00 & 7.7 \\
\hline WH 595 & 1.80 & 5.93 & 31.00 & 29.00 & 149.00 & 12.67 & 43.00 & 68.30 & 3455.00 & 2251.33 & 3409.67 & 1203.67 & 1158.34 & 7.6 \\
\hline WH 712 & 2.67 & 5.80 & 25.33 & 20.33 & 154.67 & 19.33 & 44.67 & 68.10 & 3317.33 & 2014.00 & 3247.33 & 1303.33 & 1233.33 & 7.5 \\
\hline $\begin{array}{l}\mathrm{KO} 123 \\
\mathrm{KYZ} \quad \mathrm{K} 2 \mathrm{~K}\end{array}$ & 1.40 & 6.53 & 48.33 & 29.33 & 131.67 & 11.00 & 43.67 & 68.27 & 2380.00 & 1519.00 & 2805.33 & 861.00 & 1286.33 & 7.4 \\
\hline & 1.30 & 6.03 & 48.33 & 30.33 & 131.67 & 10.33 & 39.33 & 67.80 & 2194.00 & 1284.00 & 2292.00 & 910.00 & 1008.00 & 7.5 \\
\hline HD 2793 & 2.40 & 5.53 & 28.33 & 20.33 & 151.67 & 18.67 & 44.00 & 68.37 & 3042.33 & 2177.00 & 3525.00 & 865.33 & 1348.00 & 7.5 \\
\hline WH 800 & 1.63 & 5.87 & 42.00 & 24.67 & 138.00 & 11.67 & 51.33 & 66.70 & 3172.00 & 2133.67 & 3287.33 & 1038.33 & 1153.66 & 7.5 \\
\hline WH 1003 & 2.80 & 6.40 & 35.33 & 21.33 & 144.67 & 21.33 & 51.67 & 67.80 & 3266.67 & 2143.33 & 3431.33 & 1123.34 & 1288.00 & 7.4 \\
\hline Glupro & 3.10 & 8.67 & 51.00 & 19.67 & 129.00 & 29.33 & 59.00 & 69.47 & 1861.33 & 1188.00 & 2348.33 & 673.33 & 1160.33 & 5.3 \\
\hline $\mathrm{CD}(5 \%)$ & 0.14 & 0.19 & 2.19 & 1.98 & 2.19 & 1.87 & 2.28 & 1.17 & 301.83 & 261.80 & 387.43 & 191.79 & 114.96 & 0.41 \\
\hline
\end{tabular}

$\mathrm{MTi}=$ mixing time $(\mathrm{min}), \mathrm{DS}=$ Dough strength $(\mathrm{cm}), \mathrm{RDD}=$ rate of dough development $\left({ }^{\circ}\right), \mathrm{RDW}=\mathrm{Rate}$ of dough weakening $\left({ }^{\circ}\right)$, MTo $=$ Mixing tolerance $\left({ }^{\circ}\right)$, DDA $=$ Dough development area $\left(\mathrm{cm}^{2}\right)$, BS $=$ Baking strength $\left(\mathrm{cm}^{2}\right), \mathrm{PT}=$ Paste temperature $\left({ }^{\circ} \mathrm{C}\right), \mathrm{PV}=$ Peak Viscosity $(\mathrm{rpm}), \mathrm{HV}=$ Hold viscosity $(\mathrm{rpm}), \mathrm{FV}=$ Final Viscosity $(\mathrm{rpm}), \mathrm{Bd}=$ Breakdown $(\mathrm{rpm}), \mathrm{Sb}=$ Setback $(\mathrm{rpm}), \mathrm{CS}=$ chapati score

Table 5. Mean performance of cultivars and genetic stocks evaluated for mixographic and starch pasting characteristics during second year.

\begin{tabular}{|c|c|c|c|c|c|c|c|c|c|c|c|c|c|c|}
\hline Genotype & MTi & DS & RDD & RDW & MTo & DDA & BS & PT & $\mathrm{PV}$ & HV & FV & Bd & Sb & CS \\
\hline $8 \mathrm{~A}$ & 1.69 & 5.23 & 23.00 & 22.67 & 149.33 & 12.67 & 43.00 & 68.57 & 3218.00 & 2452.67 & 4063.00 & 765.33 & 1610.33 & 7.9 \\
\hline $9 \mathrm{D}$ & 2.02 & 5.17 & 22.33 & 23.67 & 150.22 & 15.67 & 44.33 & 68.97 & 3508.67 & 2680.67 & 4427.33 & 828.00 & 1746.66 & 7.8 \\
\hline C 273 & 2.01 & 5.80 & 25.00 & 21.33 & 146.67 & 18.67 & 47.33 & 69.53 & 3190.00 & 2388.67 & 3914.67 & 801.33 & 1526.00 & 8.0 \\
\hline C 306 & 1.61 & 5.63 & 27.33 & 25.00 & 143.56 & 15.00 & 44.00 & 69.87 & 2927.00 & 2257.33 & 3956.33 & 669.67 & 1699.00 & 8.1 \\
\hline C 518 & 1.29 & 6.27 & 34.67 & 28.33 & 133.78 & 13.33 & 46.00 & 69.60 & 2694.33 & 2033.33 & 3750.00 & 661.00 & 1716.67 & 8.1 \\
\hline C 591 & 1.64 & 5.63 & 25.33 & 18.67 & 146.22 & 18.33 & 45.00 & 68.97 & 3493.67 & 2555.00 & 4252.33 & 938.67 & 1697.33 & 8.0 \\
\hline WG 357 & 1.43 & 5.97 & 32.00 & 30.33 & 137.33 & 11.00 & 43.00 & 69.00 & 2963.67 & 1924.67 & 3513.67 & 1039.00 & 1589.00 & 7.9 \\
\hline PBW 343 & 1.13 & 5.53 & 32.00 & 23.00 & 137.33 & 11.00 & 38.67 & 71.07 & 3399.00 & 2828.67 & 4396.67 & 570.33 & 1568.00 & 7.6 \\
\hline PBW 502 & 1.05 & 5.30 & 30.00 & 22.67 & 140.00 & 9.00 & 37.33 & 71.23 & 3128.00 & 2712.00 & 4126.00 & 416.00 & 1414.00 & 7.1 \\
\hline PBW 550 & 2.14 & 6.03 & 22.67 & 17.33 & 149.78 & 18.67 & 53.33 & 69.80 & 3536.67 & 2544.67 & 4162.67 & 992.00 & 1618.00 & 7.4 \\
\hline DBW 16 & 1.49 & 4.87 & 22.33 & 23.33 & 150.22 & 11.33 & 38.33 & 70.23 & 2973.00 & 2666.33 & 4255.00 & 306.67 & 1588.67 & 7.4 \\
\hline PBW 533 & 1.18 & 5.77 & 33.33 & 27.33 & 135.56 & 9.67 & 43.67 & 70.27 & 3010.33 & 2234.33 & 3579.33 & 776.00 & 1345.00 & 7.4 \\
\hline PBW 534 & 2.19 & 5.77 & 20.33 & 23.67 & 152.89 & 20.67 & 51.00 & 69.90 & 3580.00 & 2528.33 & 4154.00 & 1051.67 & 1625.67 & 7.3 \\
\hline PBW 554 & 1.87 & 4.90 & 22.00 & 21.00 & 150.67 & 17.33 & 51.00 & 70.63 & 3376.33 & 2482.33 & 4192.00 & 894.00 & 1709.67 & 7.6 \\
\hline HI 1418 & 1.17 & 5.77 & 33.00 & 24.00 & 136.00 & 10.00 & 41.67 & 71.13 & 2623.00 & 1891.33 & 3351.00 & 731.67 & 1459.67 & 7.8 \\
\hline HI 1479 & 1.47 & 5.40 & 25.00 & 16.33 & 146.67 & 12.33 & 41.67 & 69.67 & 3305.00 & 2319.00 & 3918.00 & 986.00 & 1599.00 & 7.5 \\
\hline PBW 154 & 1.69 & 5.60 & 25.67 & 21.00 & 145.78 & 13.00 & 47.00 & 69.63 & 3256.00 & 2374.00 & 4000.67 & 882.00 & 1626.67 & 7.2 \\
\hline PBW 175 & 1.53 & 5.77 & 27.67 & 26.33 & 143.11 & 13.00 & 48.33 & 69.13 & 3662.00 & 2738.00 & 4409.00 & 924.00 & 1671.00 & 7.3 \\
\hline PBW 226 & 1.36 & 6.00 & 26.67 & 27.00 & 144.44 & 12.33 & 44.00 & 69.93 & 2979.00 & 2006.33 & 3408.67 & 972.67 & 1402.34 & 7.3 \\
\hline LOK 1 & 1.00 & 5.97 & 30.67 & 27.33 & 139.11 & 14.00 & 41.33 & 68.90 & 3583.67 & 2612.67 & 4169.00 & 971.00 & 1556.33 & 7.9 \\
\hline KO 123 & 1.63 & 5.13 & 26.00 & 16.67 & 145.33 & 12.67 & 44.00 & 70.30 & 3336.33 & 2682.67 & 4658.33 & 653.66 & 1975.66 & 7.5 \\
\hline HD 2793 & 2.65 & 4.87 & 20.67 & 11.00 & 152.44 & 21.00 & 47.67 & 70.50 & 3340.33 & 2347.00 & 4569.33 & 993.33 & 2222.33 & 7.6 \\
\hline WH 712 & 1.95 & 5.83 & 24.33 & 13.33 & 147.56 & 18.67 & 51.33 & 70.87 & 3644.67 & 2695.00 & 4391.67 & 949.67 & 1696.67 & 7.3 \\
\hline WH 1003 & 3.03 & 5.20 & 14.33 & 21.67 & 160.89 & 27.33 & 50.33 & 69.67 & 3800.33 & 2941.67 & 4552.67 & 858.66 & 1611.00 & 7.4 \\
\hline CD (5\%) & 0.23 & 0.43 & 3.86 & 3.61 & 3.86 & 2.30 & 4.06 & 1.32 & 535.36 & 336.47 & 575.32 & 95.04 & 63.99 & 0.31 \\
\hline
\end{tabular}

$\mathrm{MTi}=$ mixing time $(\mathrm{min}), \mathrm{DS}=$ Dough strength $(\mathrm{cm}), \mathrm{RDD}=$ rate of dough development $\left({ }^{\circ}\right), \mathrm{RDW}=\mathrm{Rate}$ of dough weakening $\left({ }^{\circ}\right)$, MTo $=$ Mixing tolerance $\left({ }^{\circ}\right)$, DDA $=$ Dough development area $\left(\mathrm{cm}^{2}\right)$, BS = Baking strength $\left(\mathrm{cm}^{2}\right), \mathrm{PT}=$ Paste temperature $\left({ }^{\circ} \mathrm{C}\right), \mathrm{PV}=$ Peak Viscosity $(\mathrm{rpm}), \mathrm{HV}=$ Hold viscosity $(\mathrm{rpm}), \mathrm{FV}=$ Final Viscosity $(\mathrm{rpm}), \mathrm{Bd}=$ Breakdown $(\mathrm{rpm}), \mathrm{Sb}=$ Setback $(\mathrm{rpm}), \mathrm{CS}=$ chapati score 
Kumar S. et al. / J. Appl. \& Nat. Sci. 10 (2): 723 - 740 (2018)

Table 6a. Analysis of variance for starch pasting characters evaluated for C 273/PBW 343//PBW 343 population

\begin{tabular}{llllllll}
\hline $\begin{array}{l}\text { Source of } \\
\text { Variation }\end{array}$ & $\begin{array}{l}\text { Degree of } \\
\text { freedom }\end{array}$ & $\begin{array}{l}\text { Paste } \\
\text { ture }\end{array}$ & Tempera- & Peak Viscosity & Hold viscosity & Final Viscosity & Breakdown \\
\hline Replication & 2 & 0.33 & 140856.90 & 5781.33 & 212650.70 & 40017.78 \\
Treatment & 71 & $3.41^{* *}$ & $875789.30^{* *}$ & $589117.90^{* *}$ & $1544928.00^{* *}$ & $147150.40^{* *}$ & 45590.89 \\
Error & 142 & 0.34 & 288621.80 & 156992.30 & 293514.20 & 37847.86 \\
\hline
\end{tabular}

* Significant at $5 \%$ level, ${ }^{* *}$ Significant at $1 \%$ level

Table 6b. Analysis of variance for starch pasting characters evaluated for C 306/PBW 534//PBW 534 population

\begin{tabular}{lllllllll}
\hline $\begin{array}{l}\text { Source of } \\
\text { Variation }\end{array}$ & $\begin{array}{l}\text { Degree of } \\
\text { freedom }\end{array}$ & $\begin{array}{l}\text { Paste Tem- } \\
\text { perature }\end{array}$ & $\begin{array}{l}\text { Peak } \\
\text { cosity }\end{array}$ & $\begin{array}{l}\text { Hold } \\
\text { cosity }\end{array}$ & $\begin{array}{l}\text { Final } \\
\text { cosity }\end{array}$ & Vis- & Breakdown & Setback \\
\hline Replication & 2 & 17.34 & 111459.60 & 171552.00 & 354133.30 & 69672.89 & 160981.30 \\
Treatment & 71 & 22.32 & $757208.30^{* *}$ & $\begin{array}{l}388919.00^{* *} \\
1468623.00^{* *}\end{array}$ & $312885.00^{* *}$ & $505253.80^{* *}$ \\
Error & 142 & 20.87 & 384099.60 & 101622.00 & 298525.30 & 200303.70 & 94611.53 \\
\hline
\end{tabular}

*Significant at $5 \%$ level, ** Significant at $1 \%$ level

Table 6c. Analysis of variance for starch pasting characters evaluated for C 518/PBW 343//PBW 343 population

\begin{tabular}{|c|c|c|c|c|c|c|c|}
\hline $\begin{array}{l}\text { Source of } \\
\text { Variation }\end{array}$ & $\begin{array}{l}\text { Degree of } \\
\text { freedom }\end{array}$ & $\begin{array}{l}\text { Paste Tem- } \\
\text { perature }\end{array}$ & $\begin{array}{l}\text { Peak Vis- } \\
\text { cosity }\end{array}$ & $\begin{array}{l}\text { Hold } \\
\text { cosity }\end{array}$ & $\begin{array}{l}\text { Final Viscos- } \\
\text { ity }\end{array}$ & Breakdown & Setback \\
\hline Replication & 2 & 46.98 & 250713.00 & 48327.80 & 103189.90 & 101414.40 & \\
\hline Treatment & 81 & 44.63 & $622589.40^{* *}$ & $490051.40^{* *}$ & $4.00^{* *}$ & 107376.70** & $4.40^{* *}$ \\
\hline Error & 162 & 44.89 & 138114.60 & 116916.70 & 454510.40 & 67139.94 & 135035.40 \\
\hline
\end{tabular}

*Significant at $5 \%$ level, ** Significant at $1 \%$ level

PBW 534 which gave a mixing time of $2.18 \mathrm{~min}$. The other parent, C 306, gave a mixing time of 1.6 min. In case of population ' $C$ ' the parental values of mixing time were observed to be $1.3 \mathrm{~min}$ and 1.4 min for C 518 and PBW 343 respectively. Out of 80 genotypes in this population, 78 were found to range between the parental values whereas 2 genotypes gave mixing time values higher than PBW 343.

Dough strength is the ability of wheat flour to offer resistance to the stretching pressure and is measured as the height of the mixographic curve at the peak in $\mathrm{cms}$. The set of genotypes showed marked differences for dough strength in first year. The advanced lines group showed high values for dough strength followed by tall wheats. However the highest value of dough strength was recorded for WG $357(7.23 \mathrm{~cm})$ from tall wheats group. These two groups were followed by commercial varieties and than by genetic stocks. The lowest value of dough strength was recorded to be $4.97 \mathrm{~cm}$ for DI 9. C 306 from which DI 9 is derived gave a higher value of $6.33 \mathrm{~cm}$, whereas $C$ $591(5.60 \mathrm{~cm})$ and its derivative DI $105(5.70 \mathrm{~cm})$ gave equivalent values of dough strength. The winter wheat, Glupro having high protein content, gave high value of dough strength recorded at $8.67 \mathrm{~cm}$. In second year, the released varieties known for quality group gave high values of dough strength followed by tall wheats group. The tall wheat C 518 gave highest value of $6.27 \mathrm{~cm}$ for the season. The commercially grown wheats and the advanced lines gave comparable value but lower than the above two groups. The genetic stocks however gave lowest values in this season with HD 2793 giving lowest value of $4.87 \mathrm{~cm}$ in the group and comparable to the commercially grown wheat DBW 16. PBW 554, an advanced line which gave a high value of above $7 \mathrm{~cm}$ in first year however failed to give high value of dough strength in second year, recording a value of 4.90 $\mathrm{cm}$ only. In general also the dough strength values recorded were lower for the second year samples as compared to the first year. The variation in the values of dough strength was normally distributed in populations ' $A$ ' and ' $C$ ', where as in population ' $B$ ' the variation was almost equally distributed in to different classes. The transgressive segregants on higher side were observed in all the three cases. In population ' $A$ ' all the 70 genotypes gave dough strength value higher than that of $C 273$ $(5.6 \mathrm{~cm})$ whereas the other parent, PBW 343, gave a value of $5.4 \mathrm{~cm}$. In population 'B' the parents C 306 and PBW 534 gave dough strength values of $6.4 \mathrm{~cm}$ and $6.0 \mathrm{~cm}$ respectively. 44 genotypes out of 70 genotypes in this population gave dough strength values higher than that of $C 306,8$ genotypes were found to have values in the parental range whereas 18 genotypes yielded values lower than that of PBW 534. In population ' $C$ ' the parents C 518 and PBW 343 gave values of 6.2 $\mathrm{cm}$ and $5.9 \mathrm{~cm}$ respectively. 5 genotypes out of 80 gave values in the parental range whereas 70 were having higher values than those of C 518. 5 genotypes gave values lower to PBW 343.

Rate of dough development is the rate at which dough is developed on mixing flour with water and is represented by the angle which the mixing curve forms with the longitudinal line passing through the centre of the peak. Rate of dough development was found to be significantly higher for tall wheats in comparison to other groups of genotypes in first year. Commercial wheat PBW 343 with lowest mixing time, however, showed highest rate of dough development i.e., $51.67^{\circ}$. The lowest rate of dough development, as a consequence of 
Kumar S. et al. / J. Appl. \& Nat. Sci. 10 (2): 723 - 740 (2018)

Table 7. Performance of ' $A$ ' population for mixographic and starch pasting characteristics

\begin{tabular}{|c|c|c|c|c|c|c|c|c|c|c|c|c|c|c|}
\hline Entry & MTi & DS & RDD & RDW & MTo & DDA & BS & $\begin{array}{l}\text { PT } \\
\end{array}$ & PV & HV & FV & Sb & Bd & CS \\
\hline 1 & 3.3 & 6.1 & 23 & 17 & 140 & 28 & 50 & 68.70 & 2476.33 & 1490.00 & 3440.00 & 986.33 & 1950.00 & 7.6 \\
\hline 2 & 3.1 & 6.4 & 26 & 21 & 133 & 24 & 46 & 68.10 & 3038.00 & 1799.33 & 3877.67 & 1238.67 & 2078.33 & 7.7 \\
\hline 3 & 2.8 & 6 & 22 & 18 & 140 & 20 & 47 & 69.10 & 3165.33 & 1909.00 & 4574.00 & 1258.33 & 2667.00 & 7.6 \\
\hline 4 & 2.8 & 7.8 & 33 & 26 & 121 & 29 & 59 & 67.80 & 3130.00 & 1784.00 & 3752.00 & 1346.00 & 1968.00 & 7.7 \\
\hline 5 & 2.9 & 6.5 & 25 & 22 & 133 & 25 & 50 & 68.27 & 3080.33 & 1827.67 & 3954.67 & 1252.67 & 2127.00 & 7.7 \\
\hline 6 & 3 & 6.5 & 29 & 26 & 125 & 25 & 49 & 68.53 & 2856.00 & 1798.00 & 4137.67 & 1058.00 & 2339.67 & 7.6 \\
\hline 7 & 3.5 & 6.3 & 22 & 29 & 129 & 28 & 47 & 67.83 & 4234.33 & 2043.33 & 4456.67 & 1191.00 & 2413.67 & 7.5 \\
\hline 8 & 2.6 & 6.7 & 31 & 31 & 118 & 22 & 45 & 69.53 & 3582.33 & 2179.33 & 4297.00 & 1403.00 & 2117.67 & 7.7 \\
\hline 9 & 3.3 & 6 & 21 & 25 & 134 & 28 & 47 & 68.97 & 3429.67 & 1938.33 & 4027.67 & 1491.33 & 2089.33 & 7.6 \\
\hline 10 & 2.8 & 7.7 & 32 & 34 & 114 & 27 & 58 & 67.10 & 2645.00 & 1340.67 & 3117.33 & 1304.33 & 1776.67 & 7.2 \\
\hline 11 & 2.8 & 7 & 31 & 23 & 126 & 25 & 49 & 67.97 & 3522.00 & 2391.00 & 4085.67 & 1786.33 & 2627.33 & 7.6 \\
\hline 12 & 2.5 & 7.1 & 33 & 32 & 115 & 24 & 50 & 68.83 & 2977.67 & 1714.00 & 3910.00 & 1326.33 & 2267.00 & 7.8 \\
\hline 13 & 3.2 & 6.7 & 26 & 31 & 123 & 27 & 51 & 68.83 & 2548.67 & 1406.00 & 3458.00 & 1142.67 & 2052.00 & 7.6 \\
\hline 14 & 3.5 & 7.2 & 24 & 29 & 127 & 35 & 52 & 62.83 & 2330.00 & 1573.33 & 3855.67 & 775.33 & 2366.00 & 7.3 \\
\hline 15 & 2.9 & 7.8 & 27 & 30 & 123 & 32 & 62 & 69.37 & 2427.67 & 1511.33 & 3836.67 & 916.33 & 2325.33 & 7.6 \\
\hline 16 & 2.9 & 8.4 & 35 & 41 & 104 & 31 & 62 & 67.13 & 3245.33 & 2023.33 & 4366.00 & 1223.33 & 2365.67 & 7.5 \\
\hline 17 & 3.1 & 7 & 26 & 25 & 129 & 30 & 57 & 69.13 & 2838.67 & 1733.00 & 4115.67 & 1105.67 & 2382.67 & 7.6 \\
\hline 18 & 3 & 7.7 & 34 & 38 & 108 & 31 & 57 & 69.13 & 2845.67 & 1733.67 & 3807.67 & 1112.00 & 2074.00 & 7.7 \\
\hline 19 & 3.7 & 7.5 & 26 & 31 & 123 & 38 & 63 & 68.27 & 3466.33 & 2177.33 & 4814.67 & 1289.00 & 2637.33 & 7.4 \\
\hline 20 & 3.2 & 8.8 & 35 & 40 & 105 & 36 & 65 & 68.93 & 3185.67 & 1900.00 & 4181.33 & 1285.67 & 2281.33 & 7.5 \\
\hline 21 & 4.8 & 7.9 & 22 & 26 & 132 & 47 & 75 & 61.60 & 2273.33 & 1053.67 & 2415.33 & 1219.67 & 1361.67 & 7.7 \\
\hline 22 & 4.6 & 7.6 & 23 & 32 & 125 & 41 & 63 & 67.07 & 2716.33 & 1430.00 & 3335.33 & 1276.33 & 1893.67 & 7.7 \\
\hline 23 & 4.3 & 7.6 & 24 & 30 & 126 & 43 & 67 & 68.83 & 2308.33 & 1108.00 & 2772.00 & 1200.33 & 1730.67 & 7.9 \\
\hline 24 & 4.9 & 7.1 & 24 & 21 & 135 & 45 & 64 & 68.13 & 3531.00 & 1704.00 & 4682.67 & 1527.00 & 2678.67 & 7.5 \\
\hline 25 & 3.8 & 7.9 & 20 & 26 & 134 & 44 & 90 & 68.70 & 2939.67 & 1529.33 & 3747.00 & 1410.33 & 2217.67 & 7.6 \\
\hline 26 & 2.5 & 6.9 & 23 & 34 & 123 & 25 & 53 & 67.07 & 3595.33 & 2366.33 & 4612.67 & 1229.00 & 2246.33 & 7.6 \\
\hline 27 & 3.7 & 6.3 & 22 & 28 & 130 & 24 & 44 & 67.43 & 3192.00 & 2123.67 & 4428.67 & 1068.33 & 2305.00 & 7.7 \\
\hline 28 & 3.3 & 6.7 & 25 & 35 & 120 & 28 & 53 & 61.67 & 3445.33 & 2270.67 & 4545.33 & 1174.67 & 2274.67 & 7.5 \\
\hline 29 & 3.1 & 6.5 & 21 & 34 & 125 & 26 & 52 & 67.87 & 3162.67 & 2093.33 & 4435.33 & 1069.33 & 2342.00 & 7.7 \\
\hline 30 & 3.1 & 6.9 & 26 & 32 & 122 & 28 & 53 & 68.13 & 2875.67 & 1748.67 & 4224.00 & 1127.00 & 2475.33 & 7.5 \\
\hline 31 & 3.7 & 6.5 & 23 & 30 & 127 & 32 & 56 & 69.27 & 3557.00 & 2304.67 & 5009.33 & 1252.33 & 2704.00 & 7.6 \\
\hline 32 & 3.3 & 7.5 & 28 & 37 & 115 & 31 & 58 & 68.10 & 3571.67 & 2359.67 & 5181.67 & 1212.00 & 2822.00 & 7.6 \\
\hline 33 & 3.1 & 7.2 & 32 & 34 & 114 & 26 & 59 & 68.37 & 3490.33 & 2337.67 & 4987.00 & 1152.67 & 2649.33 & 7.5 \\
\hline 34 & 2.7 & 6.5 & 25 & 36 & 119 & 24 & 46 & 67.67 & 4066.00 & 2399.00 & 4419.67 & 1667.00 & 2020.67 & 7.4 \\
\hline 35 & 3.4 & 6.7 & 21 & 32 & 127 & 32 & 55 & 68.53 & 3200.67 & 1965.00 & 4432.00 & 1235.67 & 2467.00 & 7.5 \\
\hline 36 & 4.5 & 7.3 & 18 & 34 & 128 & 44 & 66 & 69.53 & 3669.67 & 2318.33 & 4809.67 & 1349.33 & 2491.33 & 7.4 \\
\hline 37 & 4.8 & 6.9 & 19 & 30 & 131 & 42 & 65 & 69.67 & 3591.67 & 2150.67 & 4895.00 & 1441.00 & 2744.33 & 7.5 \\
\hline 38 & 4 & 6.5 & 24 & 35 & 121 & 33 & 55 & 68.83 & 3804.33 & 2160.00 & 4388.67 & 1644.33 & 2228.67 & 7.4 \\
\hline 39 & 3.3 & 6.2 & 18 & 29 & 133 & 27 & 56 & 67.70 & 4052.00 & 2606.67 & 5082.67 & 1445.33 & 2476.00 & 7.5 \\
\hline 40 & 3.6 & 7 & 26 & 37 & 117 & 33 & 54 & 69.37 & 3357.33 & 2164.00 & 4986.00 & 860.00 & 2822.00 & 7.6 \\
\hline 41 & 3.2 & 6.3 & 20 & 26 & 134 & 28 & 52 & 69.10 & 2990.67 & 1862.33 & 4595.67 & 1128.33 & 2733.33 & 7.6 \\
\hline 42 & 3 & 6.7 & 23 & 36 & 121 & 25 & 51 & 68.83 & 2964.33 & 1807.00 & 4110.33 & 1157.33 & 2303.33 & 7.6 \\
\hline 43 & 2.9 & 6.4 & 24 & 30 & 126 & 27 & 49 & 67.23 & 4394.33 & 3006.33 & 5728.00 & 1388.00 & 2721.67 & 7.5 \\
\hline 44 & 3.5 & 6.5 & 20 & 27 & 133 & 30 & 54 & 68.70 & 4143.67 & 3091.33 & 5951.67 & 1052.67 & 2860.33 & 7.5 \\
\hline 45 & 2.7 & 6.7 & 30 & 33 & 117 & 22 & 45 & 68.40 & 2927.00 & 1775.00 & 3837.67 & 1153.33 & 2084.00 & 7.8 \\
\hline 46 & 3.9 & 6.2 & 15 & 18 & 147 & 37 & 60 & 69.33 & 3818.00 & 2173.67 & 4753.67 & 1641.00 & 2580.00 & 7.4 \\
\hline 47 & 4.2 & 5.6 & 13 & 21 & 146 & 33 & 49 & 69.50 & 3674.67 & 2083.00 & 4609.33 & 1591.67 & 2526.33 & 7.1 \\
\hline 48 & 3.4 & 6.7 & 19 & 21 & 140 & 32 & 62 & 68.80 & 3597.00 & 2312.00 & 5159.67 & 1285.00 & 2847.67 & 7.7 \\
\hline 49 & 3.5 & 6.4 & 17 & 26 & 137 & 32 & 55 & 68.40 & 3982.00 & 2290.33 & 4227.67 & 1691.67 & 1937.33 & 7.5 \\
\hline 50 & 3.7 & 6.4 & 16 & 29 & 135 & 34 & 54 & 61.77 & 4154.33 & 2731.67 & 5432.00 & 1422.67 & 2700.33 & 7.3 \\
\hline 51 & 2.7 & 6.8 & 19 & 24 & 137 & 27 & 58 & 69.67 & 3988.33 & 2761.67 & 5434.67 & 1226.67 & 2673.00 & 7.5 \\
\hline 52 & 4.6 & 6.7 & 18 & 23 & 139 & 41 & 64 & 69.40 & 3639.67 & 2426.00 & 5714.33 & 1213.67 & 3288.33 & 7.6 \\
\hline 53 & 4.3 & 5.8 & 14 & 20 & 146 & 37 & 58 & 69.67 & 3691.67 & 2549.67 & 5881.67 & 1142.00 & 3332.00 & 7.3 \\
\hline 54 & 3.2 & 6.6 & 17 & 23 & 140 & 29 & 58 & 69.87 & 3453.67 & 2240.33 & 5050.33 & 1222.33 & 2894.00 & 7.1 \\
\hline 55 & 3.2 & 5.6 & 18 & 30 & 132 & 25 & 45 & 66.67 & 4477.67 & 3211.33 & 6023.67 & 1265.00 & 2812.33 & 7.3 \\
\hline 56 & 4.6 & 6.5 & 20 & 16 & 144 & 37 & 60 & 69.53 & 3632.67 & 2331.67 & 5405.67 & 1302.33 & 3074.00 & 7.0 \\
\hline 57 & 3 & 7.2 & 22 & 28 & 130 & 26 & 57 & 66.53 & 3155.33 & 1928.67 & 4272.67 & 1226.67 & 2344.00 & 7.2 \\
\hline 58 & 3.2 & 6.9 & 24 & 39 & 117 & 26 & 56 & 67.57 & 3050.33 & 1901.00 & 4132.00 & 1149.33 & 2231.00 & 7.3 \\
\hline 59 & 4 & 6.7 & 23 & 25 & 132 & 33 & 56 & 67.70 & 3530.33 & 2109.33 & 4613.67 & 1427.67 & 2512.33 & 7.5 \\
\hline 60 & 3.7 & 6.7 & 19 & 42 & 119 & 32 & 52 & 67.27 & 3753.67 & 2341.67 & 4676.33 & 1412.00 & 2334.67 & 7.6 \\
\hline 61 & 3.4 & 7.8 & 29 & 35 & 116 & 33 & 61 & 65.80 & 3810.33 & 2349.33 & 4715.00 & 1461.00 & 2365.67 & 7.5 \\
\hline 62 & 4 & 6.9 & 26 & 39 & 115 & 36 & 56 & 66.13 & 3013.67 & 1798.33 & 4071.00 & 1215.33 & 2274.67 & 7.4 \\
\hline 63 & 3.3 & 6.7 & 29 & 39 & 112 & 28 & 55 & 66.53 & 2168.00 & 1279.33 & 3240.33 & 889.33 & 1964.33 & 7.7 \\
\hline 64 & 3.2 & 6.7 & 23 & 44 & 113 & 28 & 52 & 66.40 & 2893.67 & 1696.33 & 3715.33 & 1197.33 & 2019.00 & 7.5 \\
\hline 65 & 3.5 & 6.8 & 22 & 37 & 121 & 29 & 49 & 67.30 & 2960.67 & 1729.67 & 3927.00 & 1229.67 & 2197.33 & 7.6 \\
\hline 66 & 3.3 & 6 & 16 & 30 & 134 & 29 & 48 & 66.70 & 3904.33 & 2398.67 & 4883.00 & 1505.67 & 2484.33 & 7.5 \\
\hline 67 & 3.2 & 6 & 22 & 31 & 127 & 26 & 47 & 66.23 & 3650.33 & 2314.33 & 4632.00 & 1336.00 & 2317.67 & 7.5 \\
\hline
\end{tabular}


Kumar S. et al. / J. Appl. \& Nat. Sci. 10 (2): 723 - 740 (2018)

\begin{tabular}{|c|c|c|c|c|c|c|c|c|c|c|c|c|c|c|}
\hline 68 & 4.5 & 7.1 & 22 & 36 & 122 & 42 & 59 & 66.67 & 2251.33 & 1357.67 & 3796.00 & 893.67 & 2105.00 & 7.3 \\
\hline 69 & 3.1 & 6.9 & 23 & 30 & 127 & 31 & 56 & 66.80 & 4067.67 & 2511.33 & 4938.67 & 1556.33 & 2427.33 & 7.5 \\
\hline 70 & 3.7 & 6.8 & 25 & 36 & 119 & 30 & 54 & 66.70 & 3497.67 & 2247.00 & 4660.00 & 1250.67 & 2446.33 & 7.5 \\
\hline C 273 & 2.15 & 5.6 & 22 & 22 & 136 & 18 & 49 & 69.53 & 3190.00 & 2388.67 & 3914.67 & 801.33 & 1526.00 & 8.2 \\
\hline \multirow{2}{*}{$\begin{array}{l}\text { PBW } \\
343\end{array}$} & 1.25 & 5.4 & 31 & 20 & 129 & 9 & 36 & 71.07 & 3399.00 & 2828.67 & 4396.67 & 570.33 & 1568.00 & 7.7 \\
\hline & & & & & & & & ns & 879.26 & 647.1 & 892.73 & 304.92 & 390.92 & \\
\hline
\end{tabular}

$\mathrm{MTi}=$ mixing time $(\mathrm{min}), \mathrm{DS}=$ Dough strength $(\mathrm{cm}), \mathrm{RDD}=$ rate of dough development $\left({ }^{\circ}\right), \mathrm{RDW}=\mathrm{Rate}$ of dough weakening $\left({ }^{\circ}\right)$, MTo $=$ Mixing tolerance $\left({ }^{\circ}\right)$, DDA $=$ Dough development area $\left(\mathrm{cm}^{2}\right)$, BS $=$ Baking strength $\left(\mathrm{cm}^{2}\right), \mathrm{PT}=$ Paste temperature $\left({ }^{\circ} \mathrm{C}\right), \mathrm{PV}=$ Peak Viscosity $(\mathrm{rpm}), \mathrm{HV}=$ Hold viscosity $(\mathrm{rpm}), \mathrm{FV}=$ Final Viscosity $(\mathrm{rpm}), \mathrm{Bd}=$ Breakdown $(\mathrm{rpm}), \mathrm{Sb}=$ Setback $(\mathrm{rpm}), \mathrm{CS}=$ Chapati score

highest mixing time, was recorded for DI 9 $\left(16.67^{\circ}\right)$. The trend observed was that the genotypes with high mixing time showed low rate of dough development. The winter wheat Glupro however had a high rate of dough development $\left(51^{\circ}\right)$ in spite of a higher mixing time (3.10 min). In second year, the commercially grown varieties gave comparatively higher values of rate of dough development than other groups of genotypes. Highest value of rate of dough development in this season was recorded to be $34.67^{\circ}$ for ' $\mathrm{C} 518^{\prime}$ '. WH 1003 with highest mixing time (3.03 min) gave lowest value of rate of dough development i.e., $14.33^{\circ}$. Lok 1 (mixing time $1.00 \mathrm{~min}$ ) and PBW 502 (mixing time $1.05 \mathrm{~min}$ ) gave high values of $30.67^{\circ}$ and $30.00^{\circ}$ respectively. The advanced lines gave low values for rate of dough development. In this season also the rate of dough development was found to be inversely related to the mixing time. On the whole rate of dough development was lower during second year. Ideally the wheat variety with a higher rate of dough development, which implies that the energy requirements of such wheat will be lower for developing satisfactory dough, is preferred for baking. But practically the stronger wheat varieties are having lower rates of dough development due to a slower rate of water absorption by their flour. The rate of dough development was found to be normally distributed for populations ' $A$ ' and ' $C$ '. In population ' $B$ ' however, the distribution was skewed towards lower side. The population ' $C$ ' was found to have higher mean value for this trait than other two populations. In population ' $A$ ' the rate of dough development values of the parents were observed to be $22^{\circ}$ and $31^{\circ}$ for C 273 and PBW 343 respectively. 35 genotypes out of 70 were found to be in between the parental values; whereas 30 genotypes were found to give values lower than that of $C 273.5$ genotypes gave values higher than that of PBW 343. In population 'B' 40 genotypes out of 70 gave rate of dough development values in between the parental range. 30 genotypes gave lower values than that of PBW $534\left(19^{\circ}\right)$ whereas none of the genotypes gave values higher than that of $C 306\left(51^{\circ}\right)$. In population ' $C$ ' the parental values of rate of dough development were observed to be $56^{\circ}$ and $43^{\circ}$ for $\mathrm{C}$ 518 and PBW 343 respectively. 7 genotypes out of 80 were found to give values in the parental range whereas 71 genotypes gave values lower than that of PBW 343 and 2 genotypes gave higher values than that of $C 518$.

The rate of dough weakening is the rate at which the dough breakdown occurs when mixing is continued beyond optimum and is measured as the angle formed by the descending curve with the perpendicular line drawn from the apex to the base line. It is indicative of breakdown of dough strength when dough is over mixed and was found to be low for genetic stocks in first year. Entry DI 9 $\left(13.33^{\circ}\right)$ gave lowest values of rate of dough weakening. In tall wheats the rate of dough weakening was some what high with $\mathrm{C} 518$ being an exception with a rate of $15.33^{\circ}$. The highest value of rate of dough weakening was recorded to be $34.00^{\circ}$ for WG 357 , which also had the highest dough strength (7.23 $\mathrm{min})$. The advanced lines group gave high values followed by tall wheats and commercial varieties. A low rate of dough weakening was observed for Glupro $\left(19.67^{\circ}\right)$. In second year the genetic stocks again showed low values for rate of dough weakening with a group average of $15.67^{\circ}$. HD 2793 with lowest dough strength $(4.87 \mathrm{~cm})$ gave low value of $11.00^{\circ}$. The released varieties with known quality, in comparison with other groups, yielded high values of the rate of dough weakening, but the highest value in this season was again recorded for WG 357 $\left(30.33^{\circ}\right)$. The commercial varieties and the advanced lines gave intermediate values of the rate of dough weakening. The lower values of dough weakening are preferred which means that the dough losses on its strength slowly when over mixed and in general the stronger wheats with higher baking strength exhibit lower values for dough weakening. On the whole the rate of dough weakening was lower during second year. The intermediary values recorded for the tall varieties confirm to the general belief that moderately strong wheats are better suited for baking chapaties. The rate of dough weakening was observed to be normally distributed in all the three populations. Both inferior and superior transgressive segregants were observed in all the three cases, with population ' $B$ ' having high number of inferior and population ' $C$ ' having high number of superior segregants. In population 'A' 57 genotypes out of 70 gave rate of dough weakening values higher than that of C $273\left(22^{\circ}\right)$ whereas 5 genotypes gave 
Kumar S. et al. / J. Appl. \& Nat. Sci. 10 (2): 723 - 740 (2018)

Table 8. Performance of ' $\mathrm{B}$ ' population for mixographic and starch pasting characteristics.

\begin{tabular}{|c|c|c|c|c|c|c|c|c|c|c|c|c|c|c|}
\hline Entry & MTi & DS & RDD & RDW & MTo & DDA & BS & PT & PV & HV & FV & Sb & Bd & CS \\
\hline 1 & 4.7 & 7.4 & 20 & 29 & 131 & 48 & 71 & 71.37 & 2828.67 & 1557.00 & 3724.67 & 1271.67 & 2167.67 & 7.7 \\
\hline 2 & 3.1 & 7.2 & 21 & 31 & 128 & 31 & 58 & 69.83 & 2813.00 & 1852.33 & 4168.00 & 960.67 & 2315.67 & 8.0 \\
\hline 3 & 4.8 & 6.7 & 17 & 20 & 143 & 43 & 59 & 70.67 & 3652.33 & 2166.67 & 4738.33 & 1485.67 & 2505.00 & 7.9 \\
\hline 4 & 2.9 & 7.2 & 24 & 35 & 121 & 28 & 54 & 65.47 & 2618.67 & 1718.00 & 3946.00 & 900.67 & 2228.00 & 7.9 \\
\hline 5 & 2.6 & 8 & 29 & 35 & 116 & 21 & 53 & 70.50 & 3421.67 & 2346.00 & 4628.00 & 1078.67 & 2272.00 & 7.9 \\
\hline 6 & 3.6 & 7.3 & 20 & 27 & 133 & 41 & 63 & 69.53 & 2332.33 & 830.00 & 1957.33 & 1502.33 & 1126.33 & 7.9 \\
\hline 7 & 4.4 & 8.1 & 25 & 31 & 124 & 46 & 71 & 69.53 & 3450.33 & 2326.33 & 5379.00 & 1124.00 & 3052.67 & 7.4 \\
\hline 8 & 4.4 & 7.4 & 19 & 32 & 129 & 46 & 65 & 62.77 & 3056.67 & 1930.00 & 4832.67 & 968.33 & 2944.00 & 7.7 \\
\hline 9 & 3.8 & 7.8 & 22 & 27 & 131 & 43 & 72 & 68.50 & 3300.00 & 2124.33 & 5003.67 & 1149.67 & 2797.33 & 7.6 \\
\hline 10 & 3.1 & 7.9 & 32 & 34 & 114 & 32 & 58 & 70.77 & 4919.67 & 1969.67 & 4284.67 & 1082.67 & 2315.00 & 7.8 \\
\hline 11 & 3.8 & 8.6 & 30 & 40 & 110 & 45 & 71 & 70.23 & 3260.33 & 2152.00 & 4645.00 & 1108.33 & 2493.00 & 7.9 \\
\hline 12 & 3.2 & 8.7 & 28 & 34 & 118 & 40 & 75 & 70.00 & 3320.00 & 1931.67 & 4312.00 & 1388.33 & 2390.33 & 7.7 \\
\hline 13 & 4.7 & 7.9 & 25 & 26 & 129 & 50 & 74 & 71.47 & 3527.00 & 2216.33 & 4861.00 & 1310.67 & 2644.67 & 7.9 \\
\hline 14 & 4.1 & 7.8 & 20 & 29 & 131 & 46 & 70 & 70.53 & 3136.00 & 1959.33 & 4332.33 & 1176.67 & 2373.00 & 7.8 \\
\hline 15 & 4.7 & 7.8 & 20 & 17 & 143 & 52 & 76 & 69.53 & 3454.33 & 2141.33 & 4579.67 & 1438.33 & 2429.67 & 7.9 \\
\hline 16 & 4.9 & 7.1 & 17 & 17 & 146 & 50 & 68 & 70.37 & 3728.33 & 2552.33 & 5365.00 & 1176.00 & 2812.67 & 7.9 \\
\hline 17 & 4.9 & 7.9 & 19 & 34 & 127 & 49 & 71 & 71.20 & 2923.67 & 1721.67 & 4190.00 & 1202.00 & 2301.67 & 7.9 \\
\hline 18 & 3.2 & 8.1 & 30 & 32 & 118 & 38 & 61 & 69.93 & 3003.00 & 1730.33 & 3796.00 & 1272.67 & 2065.67 & 7.8 \\
\hline 19 & 5.3 & 6.5 & 21 & 26 & 133 & 50 & 62 & 70.10 & 3665.67 & 2534.00 & 5295.67 & 1131.67 & 2761.67 & 7.7 \\
\hline 20 & 3.4 & 8.1 & 24 & 28 & 128 & 38 & 71 & 70.20 & 2538.00 & 1467.33 & 3737.67 & 1070.67 & 2270.33 & 8.0 \\
\hline 21 & 4 & 6.9 & 22 & 26 & 132 & 39 & 59 & 64.33 & 2883.33 & 1716.67 & 3892.67 & 1166.67 & 2176.00 & 7.6 \\
\hline 22 & 4.6 & 7.6 & 23 & 29 & 128 & 44 & 62 & 63.67 & 3117.67 & 1856.67 & 4051.33 & 1261.00 & 2194.67 & 7.5 \\
\hline 23 & 4.1 & 7.9 & 30 & 35 & 115 & 39 & 70 & 69.80 & 3440.00 & 2010.00 & 4078.00 & 1430.00 & 2068.00 & 7.4 \\
\hline 24 & 4.1 & 6.8 & 24 & 43 & 113 & 34 & 54 & 70.10 & 2806.67 & 1548.33 & 3448.67 & 1258.33 & 1900.33 & 7.0 \\
\hline 25 & 4 & 7.3 & 23 & 37 & 120 & 40 & 61 & 70.00 & 3430.33 & 1923.67 & 4039.67 & 1464.33 & 2159.00 & 7.2 \\
\hline 26 & 4 & 7.6 & 30 & 33 & 117 & 38 & 62 & 70.27 & 3500.67 & 2325.33 & 5253.00 & 1177.00 & 2929.33 & 7.0 \\
\hline 27 & 4.6 & 7 & 20 & 29 & 131 & 42 & 65 & 70.10 & 3430.00 & 2257.33 & 5155.67 & 1172.67 & 2898.33 & 7.2 \\
\hline 28 & 3.8 & 7.5 & 21 & 33 & 126 & 36 & 62 & 69.53 & 3316.33 & 2272.33 & 5235.33 & 1044.00 & 2963.00 & 7.2 \\
\hline 29 & 3.3 & 5.6 & 17 & 22 & 141 & 25 & 46 & 72.10 & 2392.33 & 1623.00 & 3769.00 & 769.33 & 2146.00 & 7.0 \\
\hline 30 & 4.2 & 6 & 20 & 27 & 133 & 37 & 55 & 70.87 & 3330.00 & 2373.33 & 5228.33 & 956.67 & 2851.67 & 6.9 \\
\hline 31 & 5 & 8 & 18 & 26 & 136 & 51 & 72 & 64.93 & 3468.67 & 2084.00 & 4669.67 & 1385.33 & 2585.67 & 7.0 \\
\hline 32 & 4.9 & 8.1 & 28 & 23 & 129 & 50 & 67 & 70.67 & 3755.00 & 2450.00 & 5379.67 & 1305.00 & 2941.67 & 7.3 \\
\hline 33 & 4.9 & 6.7 & 17 & 16 & 147 & 45 & 62 & 71.90 & 4041.67 & 2637.00 & 5128.33 & 1404.67 & 2491.33 & 7.2 \\
\hline 34 & 4.8 & 7.2 & 26 & 31 & 123 & 42 & 60 & 71.20 & 3586.00 & 2094.67 & 4695.33 & 1491.33 & 2600.67 & 7.2 \\
\hline 35 & 5.6 & 6.8 & 25 & 22 & 133 & 46 & 58 & 70.60 & 3862.00 & 2504.67 & 5772.67 & 1357.33 & 3268.00 & 7.1 \\
\hline 36 & 5.1 & 7.6 & 24 & 25 & 131 & 52 & 69 & 72.77 & 2865.00 & 1767.00 & 4163.67 & 1098.00 & 2396.67 & 7.3 \\
\hline 37 & 4.9 & 7.4 & 25 & 25 & 130 & 40 & 62 & 71.27 & 3129.00 & 1969.00 & 4557.33 & 1160.00 & 2421.67 & 6.9 \\
\hline 38 & 5.2 & 7.2 & 20 & 28 & 132 & 50 & 66 & 69.50 & 3063.67 & 1860.67 & 4140.00 & 1223.33 & 2278.67 & 6.9 \\
\hline 39 & 5.3 & 7.6 & 18 & 27 & 135 & 50 & 73 & 71.60 & 2866.00 & 1860.33 & 4313.00 & 1005.67 & 2451.33 & 6.9 \\
\hline 40 & 5.6 & 7.8 & 23 & 28 & 129 & 47 & 66 & 70.10 & 3596.67 & 2193.67 & 4954.33 & 1403.00 & 2760.67 & 7.1 \\
\hline 41 & 5.4 & 7.4 & 18 & 30 & 132 & 45 & 66 & 72.03 & 3038.33 & 2007.33 & 4464.67 & 1031.00 & 2457.33 & 7.3 \\
\hline 42 & 5.4 & 7.1 & 20 & 21 & 139 & 37 & 64 & 72.33 & 2368.00 & 1503.00 & 3598.33 & 865.00 & 2095.33 & 7.2 \\
\hline 43 & 5.5 & 7 & 17 & 23 & 140 & 42 & 63 & 72.60 & 2799.00 & 1743.33 & 4120.00 & 1072.33 & 2376.67 & 7.0 \\
\hline 44 & 4.9 & 6.7 & 22 & 25 & 133 & 36 & 59 & 71.63 & 3146.33 & 1959.67 & 4497.00 & 1186.67 & 2537.33 & 7.2 \\
\hline 45 & 5.4 & 6.2 & 18 & 22 & 140 & 41 & 56 & 71.17 & 2981.00 & 2119.67 & 4680.00 & 861.33 & 2560.33 & 7.0 \\
\hline 46 & 5.5 & 6.1 & 17 & 22 & 141 & 42 & 54 & 72.37 & 2624.00 & 1753.00 & 4376.00 & 871.00 & 2623.00 & 7.3 \\
\hline 47 & 5.4 & 5.9 & 20 & 24 & 136 & 38 & 50 & 71.20 & 3185.67 & 2222.33 & 5145.00 & 963.33 & 2922.67 & 7.1 \\
\hline 48 & 5.7 & 5.5 & 18 & 32 & 130 & 35 & 44 & 71.33 & 3040.33 & 2080.67 & 4700.33 & 943.00 & 2601.67 & 7.4 \\
\hline 49 & 4.7 & 6.7 & 24 & 25 & 131 & 36 & 58 & 69.93 & 3554.67 & 2327.67 & 5480.33 & 1227.00 & 3152.67 & 7.3 \\
\hline 50 & 5.1 & 6.2 & 24 & 22 & 134 & 35 & 57 & 69.97 & 3454.00 & 2326.00 & 5380.00 & 1128.00 & 3054.00 & 7.5 \\
\hline 51 & 5.5 & 6 & 19 & 20 & 141 & 38 & 54 & 72.73 & 2955.67 & 1945.33 & 4470.00 & 1009.33 & 2523.67 & 7.1 \\
\hline 52 & 4.9 & 6.1 & 18 & 16 & 146 & 40 & 59 & 72.60 & 2685.67 & 1783.67 & 4124.33 & 902.00 & 2340.67 & 7.0 \\
\hline 53 & 4.9 & 6.1 & 19 & 34 & 127 & 36 & 55 & 72.03 & 3184.00 & 2249.33 & 5097.00 & 934.67 & 2847.67 & 7.4 \\
\hline 54 & 5 & 4.9 & 16 & 22 & 142 & 38 & 56 & 66.40 & 3122.00 & 2077.00 & 4347.00 & 1045.00 & 2270.00 & 7.0 \\
\hline 55 & 4.2 & 5.5 & 18 & 24 & 138 & 30 & 51 & 71.37 & 3265.33 & 2199.67 & 4459.00 & 1065.67 & 2259.33 & 7.2 \\
\hline 56 & 2.3 & 5.7 & 22 & 29 & 129 & 18 & 37 & 63.90 & 3392.00 & 2306.00 & 4798.33 & 1086.00 & 2492.33 & 7.2 \\
\hline 57 & 2.7 & 5.4 & 25 & 20 & 135 & 18 & 39 & 69.70 & 3830.00 & 2519.33 & 4944.67 & 1510.67 & 2425.33 & 7.1 \\
\hline 58 & 5.4 & 6.5 & 23 & 25 & 132 & 41 & 61 & 65.73 & 2624.00 & 2091.67 & 4460.00 & 899.00 & 2368.33 & 7.1 \\
\hline 59 & 5.3 & 5.4 & 16 & 25 & 139 & 41 & 60 & 63.20 & 3348.33 & 2389.67 & 5160.33 & 958.67 & 2770.67 & 7.0 \\
\hline 60 & 5.2 & 5.5 & 18 & 26 & 136 & 30 & 52 & 62.60 & 2311.67 & 2637.33 & 4234.67 & 1056.00 & 1952.33 & 7.0 \\
\hline 61 & 5.6 & 69 & 22 & 26 & 132 & 50 & 66 & 71.33 & 2651.67 & 1696.33 & 4156.67 & 955.33 & 2460.33 & 7.2 \\
\hline 62 & 4.9 & 5.8 & 18 & 18 & 144 & 35 & 59 & 71.77 & 2924.33 & 1926.33 & 4369.00 & 998.00 & 2442.67 & 7.0 \\
\hline 63 & 4.9 & 5.8 & 19 & 24 & 137 & 41 & 55 & 71.07 & 3583.67 & 2249.00 & 4592.00 & 1334.67 & 2343.00 & 7.0 \\
\hline 64 & 5.3 & 6.9 & 23 & 18 & 139 & 46 & 61 & 70.37 & 3450.00 & 2046.67 & 4551.00 & 1403.33 & 2504.33 & 6.9 \\
\hline 65 & 5.2 & 5.7 & 19 & 23 & 138 & 40 & 61 & 70.23 & 3009.00 & 1743.33 & 3832.67 & 1265.67 & 2089.33 & 7.1 \\
\hline
\end{tabular}


Kumar S. et al. / J. Appl. \& Nat. Sci. 10 (2): 723 - 740 (2018)

\begin{tabular}{|c|c|c|c|c|c|c|c|c|c|c|c|c|c|c|}
\hline 66 & 5.6 & 5.2 & 21 & 27 & 132 & 43 & 59 & 73.60 & 2470.67 & 1773.00 & 4162.33 & 697.67 & 2389.33 & 7.2 \\
\hline 67 & 4.9 & 4.9 & 22 & 31 & 127 & 46 & 65 & 72.07 & 2653.33 & 1857.33 & 4593.00 & 794.33 & 2735.33 & 7.2 \\
\hline 68 & 4.8 & 5.8 & 23 & 28 & 129 & 41 & 55 & 65.03 & 2333.33 & 1499.67 & 3871.67 & 833.67 & 2372.00 & 7.2 \\
\hline 69 & 2.7 & 5.5 & 21 & 30 & 121 & 39 & 56 & 62.20 & 1649.67 & 791.67 & 2022.33 & 858.00 & 1214.00 & 7.0 \\
\hline 70 & 4.1 & 6.4 & 18 & 23 & 139 & 36 & 63 & 69.17 & 2502.00 & 1583.33 & 3695.33 & 874.33 & 2190.00 & 7.2 \\
\hline C 306 & 1.6 & 6.4 & 51 & 29 & 100 & 11 & 42 & 68.47 & 2588.00 & 1679.67 & 3132.00 & 953.67 & 1385.67 & 8.2 \\
\hline PBW 534 & 2.18 & 6 & 19 & 24 & 137 & 22 & 50 & $\begin{array}{l}69.90 \\
\text { ns }\end{array}$ & $\begin{array}{l}3580.00 \\
1007.89\end{array}$ & $\begin{array}{l}2528.33 \\
520.22\end{array}$ & $\begin{array}{l}4154.00 \\
\mathbf{8 9 5 . 8 9}\end{array}$ & $\begin{array}{l}1019.67 \\
\mathbf{3 7 0 . 2 8}\end{array}$ & $\begin{array}{l}1606.00 \\
491.71\end{array}$ & 7.4 \\
\hline
\end{tabular}

$\mathrm{MTi}=$ mixing time $(\mathrm{min}), \mathrm{DS}=$ Dough strength $(\mathrm{cm}), \mathrm{RDD}=$ rate of dough development $\left({ }^{\circ}\right)$, RDW $=$ Rate of dough weakening $\left({ }^{\circ}\right)$, MTo $=$ Mixing tolerance $\left({ }^{\circ}\right)$, DDA $=$ Dough development area $\left(\mathrm{cm}^{2}\right)$, BS $=$ Baking strength $\left(\mathrm{cm}^{2}\right), \mathrm{PT}=$ Paste temperature $\left({ }^{\circ} \mathrm{C}\right), \mathrm{PV}=$ Peak Viscosity $(\mathrm{rpm}), \mathrm{HV}=$ Hold viscosity $(\mathrm{rpm}), \mathrm{FV}=$ Final Viscosity $(\mathrm{rpm}), \mathrm{Bd}=$ Breakdown $(\mathrm{rpm}), \mathrm{Sb}=$ Setback $(\mathrm{rpm}), \mathrm{CS}=$ Chapati score

values lower than that of PBW $343\left(20^{\circ}\right) .8$ genotypes were observed to have values in the parental range. In population ' $\mathrm{B}$ ' the parents were observed to have values of $29^{\circ}$ and $24^{\circ}$ for C 306 and PBW 534 respectively. Out of 70 genotypes in this population, 23 were found to be in the parental range whereas 23 genotypes gave values higher than that of $\mathrm{C} 306$ and 24 genotypes gave values lower than that of PBW 534. In population ' $C$ ' the rate of dough weakening values for the parents were observed to be $28^{\circ}$ and $30^{\circ}$ for $\mathrm{C}$ 518 and PBW 343 respectively. 11 genotypes out of 80 were observed to have values in the parental range whereas 25 genotypes gave values lower than that of $C 518$ and 44 genotypes gave values higher than that of PBW 343.

Mixing tolerance refers to the ability of wheat dough to resist breakdown when extra energy is applied to the system. It is measured by the angle enclosed by the ascending and descending portions of the mixographic curve. It is another measure of dough weakening. In first year the mixing tolerance was found to be high in the advanced lines with PBW 534 showing a high value of $160.33^{\circ}$. The genetic stock DI 9, however, recorded the highest value of $163.33^{\circ}$ mixing time. The genetic stocks showed a lot of variation for mixing tolerance with values ranging from $131.67^{\circ}$ for $\mathrm{K}$ 0123 and $\mathrm{KYZ}$ K2K-13 to $163.33^{\circ}$ for DI 9. The commercially grown wheat PBW $343\left(128.33^{\circ}\right)$ recorded lowest value of mixing tolerance in this season. The tall wheats showed intermediate values of mixing tolerance. Glupro also yielded a low value of $129^{\circ}$ mixing tolerance. In second year, the genetic stocks gave high values for mixing tolerance with $\mathrm{WH} 1003$ recording a value of $160.89^{\circ}$. The advanced lines followed the genetic stocks with PBW 534 and PBW 554 showing values above $150^{\circ}$. The tall wheats group and the released varieties with known quality gave intermediate values for mixing tolerance, with C 518 being an exception recording lowest value of $133.78^{\circ}$ for the season. In commercially grown varieties group, DBW 16 and PBW 550 gave higher values of $150.22^{\circ}$ and $149.78^{\circ}$ respectively. The values for the mixing tolerance are almost similar for both the years of study which shows that the character is stable and can be employed for screening of the breeding materials. The variation for mixing tolerance was observed to be normally distributed in all the three populations with most of the individuals falling in between the parental ranges. However transgressive segregants on both the sides were identified in all the populations. In population ' $A$ ' the mixing tolerance of the parents was observed to be $136^{\circ}$ and $129^{\circ}$ for $C$ 273 and PBW 343 respectively. 19 genotypes out of 70 gave mixing tolerance values in between the parental range, whereas 40 genotypes gave values lower than that of PBW 343 and 11 genotypes were having values higher than that of $C 273$. In population 'B' none of the genotypes out of 70 were observed to have mixing tolerance values lower than that of $C 306\left(100^{\circ}\right)$, whereas 20 genotypes gave values higher than that of PBW 534 $\left(137^{\circ}\right)$. Remaining 50 genotypes gave values in the parental range. In population ' $C$ ' the parental values of mixing tolerance were observed to be $96^{\circ}$ and $107^{\circ}$ for C 518 and PBW 343 respectively. Out of 80 genotypes in this population 71 were found to have mixing tolerance values more than that of PBW 343 whereas 3 genotypes gave values lower than that of $C 518.6$ genotypes were observed to have mixing tolerance values in the parental range.

Dough development area is the area enclosed by the developing curve upto the peak is reached and it relates to the energy requirements for dough development. In first year the values of dough development area were found to be high for advanced lines. C 518, the tall wheat variety, gave lowest value of $9 \mathrm{~cm}^{2}$ dough development area. The highest value of $21.33 \mathrm{~cm}^{2}$ was recorded for the genetic stock WH 1003. Other genetic stocks gave values ranging from $10.33 \mathrm{~cm}^{2}$ for $\mathrm{K}$ 0123 to $21.33 \mathrm{~cm}^{2}$ (WH 1003). In commercially grown wheats group PBW 343 and PBW 502 gave low values of $10.00 \mathrm{~cm}^{2}$ and $9.31 \mathrm{~cm}^{2}$ respectively, whereas PBW $550\left(21.00 \mathrm{~cm}^{2}\right)$ and PBW $509\left(20.33 \mathrm{~cm}^{2}\right)$ recorded high values. The tall wheats barring C 518 gave intermediate values of dough development area in the season though the mean value was lowest for the group. Glupro gave a high value of $19.33 \mathrm{~cm}^{2}$. In second year the commercial wheats group gave low values with PBW 502 and PBW 533 recording values 
Kumar S. et al. / J. Appl. \& Nat. Sci. 10 (2): 723 - 740 (2018)

Table 9. Performance of ' $C$ ' population for mixographic and starch pasting characteristics .

\begin{tabular}{|c|c|c|c|c|c|c|c|c|c|c|c|c|c|c|}
\hline Entry & MTi & DS & RDD & RDW & MTo & DDA & BS & PT & PV & HV & FV & Sb & Bd & CS \\
\hline 1 & 2.1 & 7.4 & 36 & 44 & 100 & 23 & 50 & 75.43 & 2423.33 & 1526.33 & 3625.33 & 897.00 & 2099.00 & 7.6 \\
\hline$\overline{2}$ & 2.6 & 7.2 & 31 & 38 & 111 & 23 & 50 & 60.93 & 2497.00 & 1625.00 & 3777.67 & 872.00 & 2152.67 & 7.5 \\
\hline 3 & 2.1 & 7.2 & 41 & 41 & 98 & 20 & 46 & 57.07 & 2167.33 & 1363.67 & 3365.00 & 788.67 & 2001.33 & 7.2 \\
\hline 4 & 2.9 & 6.8 & 29 & 36 & 115 & 21 & 49 & 65.17 & 3266.67 & 2020.33 & 3759.33 & 1247.67 & 1739.00 & 7.4 \\
\hline 5 & 1.7 & 7.4 & 43 & 39 & 98 & 18 & 52 & 64.07 & 2632.67 & 1774.00 & 3921.33 & 858.67 & 2147.33 & 7.2 \\
\hline 6 & 3.4 & 7.1 & 27 & 33 & 120 & 32 & 54 & 57.60 & 3309.00 & 2298.33 & 4890.67 & 1010.67 & 2592.33 & 7.5 \\
\hline 7 & 3.4 & 6.7 & 22 & 35 & 123 & 30 & 53 & 63.80 & 2996.67 & 2069.00 & 4388.33 & 927.67 & 2319.33 & 7.7 \\
\hline 8 & 3.3 & 6.8 & 25 & 27 & 128 & 29 & 54 & 69.53 & 2666.33 & 1675.67 & 3656.67 & 990.67 & 1981.00 & 7.8 \\
\hline 9 & 4.7 & 7.4 & 23 & 39 & 118 & 46 & 63 & 71.53 & 3406.33 & 2385.00 & 4839.00 & 1021.33 & 2452.67 & 7.4 \\
\hline 10 & 4.4 & 6.8 & 23 & 33 & 124 & 40 & 60 & 63.77 & 3315.33 & 2298.00 & 4806.67 & 1017.33 & 2508.67 & 7.4 \\
\hline 11 & 2.7 & 6.5 & 25 & 32 & 123 & 24 & 50 & 70.60 & 2941.00 & 2252.67 & 4745.00 & 729.67 & 2534.67 & 7.4 \\
\hline 12 & 3.5 & 6.8 & 28 & 35 & 117 & 28 & 53 & 63.83 & 3033.33 & 2210.00 & 4741.00 & 823.33 & 2531.00 & 7.5 \\
\hline 13 & 3.4 & 7.9 & 35 & 38 & 107 & 33 & 61 & 63.87 & 2596.00 & 1615.33 & 4269.00 & 980.67 & 2653.67 & 7.4 \\
\hline 14 & 2.9 & 7.4 & 35 & 35 & 110 & 27 & 54 & 64.47 & 2999.00 & 1325.67 & 2816.33 & 1673.33 & 1490.67 & 7.4 \\
\hline 15 & 3 & 6.9 & 26 & 29 & 125 & 29 & 53 & 70.50 & 2972.00 & 1941.00 & 4088.00 & 1031.00 & 2146.67 & 7.5 \\
\hline 16 & 2.5 & 6.6 & 28 & 30 & 122 & 21 & 49 & 71.50 & 3181.33 & 2241.67 & 4341.00 & 939.67 & 2099.33 & 7.6 \\
\hline 17 & 2.2 & 6.8 & 31 & 26 & 123 & 21 & 51 & 71.33 & 2835.67 & 1887.67 & 4184.33 & 948.00 & 2296.67 & 7.4 \\
\hline 18 & 2.3 & 6.1 & 20 & 27 & 133 & 21 & 46 & 70.80 & 2490.67 & 1678.33 & 3601.00 & 812.33 & 1922.67 & 7.4 \\
\hline 19 & 3.5 & 5.3 & 18 & 19 & 143 & 27 & 44 & 71.50 & 3097.33 & 2103.67 & 4506.67 & 1027.00 & 2403.00 & 7.5 \\
\hline 20 & 2.3 & 7.1 & 33 & 32 & 115 & 22 & 52 & 70.90 & 3088.67 & 2024.00 & 4339.33 & 1064.67 & 2315.33 & 7.6 \\
\hline 21 & 2 & 7.7 & 42 & 39 & 99 & 21 & 63 & 69.07 & 949.33 & 187.33 & 609.67 & 762.00 & 422.33 & 7.5 \\
\hline 22 & 2.3 & 8.5 & 41 & 45 & 94 & 26 & 62 & 70.63 & 2702.33 & 1505.67 & 3217.00 & 1196.67 & 1711.33 & 7.7 \\
\hline 23 & 2.9 & 7.2 & 34 & 33 & 113 & 26 & 54 & 70.37 & 3030.67 & 1730.67 & 3401.67 & 1300.00 & 1671.00 & 7.6 \\
\hline 24 & 2.6 & 6.7 & 28 & 26 & 126 & 25 & 53 & 69.97 & 2184.33 & 1409.33 & 3352.67 & 775.00 & 1943.33 & 7.6 \\
\hline 25 & 2.9 & 7.5 & 33 & 38 & 109 & 28 & 56 & 64.60 & 2600.33 & 1763.67 & 3858.00 & 816.67 & 2091.00 & 7.4 \\
\hline 26 & 2.6 & 7 & 29 & 34 & 117 & 27 & 54 & 70.80 & 3301.33 & 2341.33 & 4608.67 & 930.00 & 2237.33 & 7.7 \\
\hline 27 & 4 & 7 & 24 & 31 & 125 & 37 & 56 & 64.77 & 2237.33 & 1196.67 & 2751.00 & 1040.67 & 1554.33 & 7.5 \\
\hline 28 & 3.1 & 7.3 & 25 & 40 & 115 & 31 & 26 & 62.93 & 3151.00 & 2173.67 & 4211.33 & 977.33 & 2037.67 & 7.7 \\
\hline 29 & 2.5 & 6.5 & 33 & 30 & 117 & 24 & 47 & 64.93 & 2611.00 & 1568.33 & 3325.67 & 1042.67 & 1757.33 & 7.4 \\
\hline 30 & 3.6 & 5.4 & 15 & 20 & 145 & 27 & 45 & 70.63 & 2987.67 & 1993.33 & 4150.33 & 1016.00 & 2046.33 & 7.4 \\
\hline 31 & 2.5 & 5.8 & 19 & 25 & 136 & 22 & 43 & 70.37 & 3194.33 & 2084.00 & 4172.00 & 1110.33 & 2088.00 & 7.8 \\
\hline 32 & 2 & 6.9 & 41 & 35 & 104 & 17 & 48 & 70.07 & 2696.33 & 1954.33 & 4017.33 & 1078.67 & 2063.00 & 7.6 \\
\hline 33 & 3.3 & 5.5 & 21 & 25 & 134 & 24 & 47 & 63.37 & 3242.00 & 2211.33 & 4424.67 & 1067.33 & 2292.00 & 7.8 \\
\hline 34 & 2.9 & 5.6 & 26 & 25 & 129 & 19 & 41 & 70.50 & 3052.67 & 2034.67 & 4176.67 & 1018.00 & 2142.00 & 7.8 \\
\hline 35 & 4.6 & 6.7 & 18 & 25 & 137 & 43 & 64 & 71.03 & 2467.00 & 1752.00 & 4301.00 & 715.00 & 2499.00 & 7.3 \\
\hline 36 & 3.8 & 6.7 & 20 & 28 & 132 & 36 & 58 & 70.23 & 2997.33 & 1766.67 & 3890.33 & 1230.67 & 2157.00 & 7.6 \\
\hline 37 & 3.9 & 7.2 & 29 & 30 & 121 & 32 & 58 & 63.23 & 1988.67 & 982.33 & 2514.33 & 1007.00 & 1532.00 & 7.7 \\
\hline 38 & 4.1 & 7.7 & 28 & 28 & 124 & 46 & 74 & 61.67 & 1918.67 & 986.00 & 2357.67 & 933.00 & 1372.00 & 7.5 \\
\hline 39 & 2.8 & 6 & 20 & 25 & 135 & 24 & 48 & 64.70 & 2319.00 & 1390.00 & 3146.33 & 929.00 & 1756.33 & 7.5 \\
\hline 40 & 3.3 & 6.6 & 19 & 28 & 133 & 28 & 54 & 71.37 & 2341.67 & 1458.33 & 3643.00 & 883.33 & 2184.67 & 7.5 \\
\hline 41 & 2 & 7.5 & 37 & 40 & 103 & 21 & 50 & 70.90 & 2593.33 & 1167.00 & 2641.33 & 1426.33 & 1474.33 & 7.6 \\
\hline 42 & 1.4 & 7.4 & 41 & 31 & 108 & 12 & 45 & 64.73 & 1959.67 & 1081.67 & 3122.67 & 878.00 & 2040.00 & 7.5 \\
\hline 43 & 1.4 & 6.2 & 35 & 28 & 117 & 15 & 46 & 70.53 & 3048.67 & 1941.67 & 4120.67 & 1107.00 & 2179.00 & 7.6 \\
\hline 44 & 1.5 & 5.9 & 30 & 31 & 119 & 14 & 42 & 67.33 & 3281.33 & 2119.67 & 3936.00 & 1161.67 & 1816.33 & 7.6 \\
\hline 45 & 2.6 & 6.3 & 28 & 22 & 130 & 22 & 49 & 70.63 & 3105.67 & 1962.00 & 3498.67 & 1144.67 & 2236.67 & 7.4 \\
\hline 46 & 2.3 & 7 & 34 & 34 & 112 & 22 & 51 & 71.07 & 2271.33 & 1568.67 & 3719.33 & 1036.00 & 2150.67 & 7.4 \\
\hline 47 & 2.1 & 7 & 34 & 39 & 107 & 20 & 46 & 70.23 & 2535.00 & 1466.67 & 3350.00 & 1068.33 & 1880.00 & 7.6 \\
\hline 48 & 2 & 6.9 & 35 & 30 & 115 & 18 & 48 & 71.07 & 2331.33 & 1376.67 & 3238.67 & 954.67 & 1862.00 & 7.5 \\
\hline 49 & 2.1 & 7.4 & 40 & 36 & 104 & 22 & 52 & 70.23 & 2717.00 & 1714.33 & 3695.67 & 1002.67 & 1981.33 & 7.5 \\
\hline 50 & 2 & 7 & 43 & 36 & 100 & 21 & 55 & 69.17 & 3374.33 & 2308.00 & 4549.33 & 1124.67 & 2259.67 & 7.5 \\
\hline 51 & 2.6 & 6.7 & 27 & 29 & 124 & 25 & 53 & 64.87 & 3387.33 & 1604.00 & 3248.33 & 1783.33 & 1644.33 & 7.4 \\
\hline 52 & 2.3 & 6.7 & 31 & 29 & 120 & 22 & 49 & 69.73 & 2975.00 & 2037.00 & 4532.67 & 938.00 & 2495.67 & 7.2 \\
\hline 53 & 3.8 & 5.5 & 13 & 21 & 146 & 32 & 51 & 65.03 & 2864.33 & 1915.00 & 4372.33 & 949.33 & 2457.33 & 7.2 \\
\hline 54 & 3.1 & 6.2 & 24 & 25 & 131 & 26 & 48 & 70.77 & 3042.67 & 1879.67 & 4014.67 & 1163.00 & 2135.00 & 7 \\
\hline 55 & 3.7 & 6.2 & 19 & 30 & 131 & 32 & 53 & 70.77 & 3804.00 & 2310.33 & 4462.33 & 1477.00 & 2152.00 & 7.3 \\
\hline 56 & 3.7 & 7.2 & 29 & 25 & 126 & 36 & 61 & 70.93 & 2665.00 & 1606.00 & 3937.00 & 1057.33 & 2329.33 & 7.4 \\
\hline 57 & 3 & 7.4 & 32 & 26 & 122 & 38 & 65 & 71.37 & 3572.67 & 2508.33 & 5359.00 & 1139.00 & 2875.67 & 7.5 \\
\hline 58 & 3.2 & 7 & 31 & 29 & 120 & 39 & 63 & 70.93 & 3515.67 & 2462.00 & 5087.33 & 1053.67 & 2625.33 & 7.5 \\
\hline 59 & 2.9 & 8.3 & 38 & 40 & 102 & 30 & 61 & 64.20 & 2644.00 & 1549.00 & 3865.67 & 1095.00 & 2316.67 & 7.2 \\
\hline 60 & 2.3 & 7.1 & 33 & 28 & 119 & 23 & 52 & 60.37 & 2728.33 & 1743.33 & 3952.00 & 985.00 & 2208.67 & 7.2 \\
\hline 61 & 2.4 & 6.8 & 32 & 23 & 125 & 35 & 56 & 65.60 & 2909.67 & 2053.33 & 4437.67 & 856.33 & 2384.33 & 7.5 \\
\hline 62 & 2.5 & 7.2 & 32 & 34 & 114 & 24 & 49 & 64.27 & 2712.67 & 1928.33 & 4116.33 & 785.33 & 2189.00 & 7.3 \\
\hline 63 & 2.7 & 6.8 & 29 & 31 & 120 & 27 & 50 & 70.80 & 3149.00 & 2195.33 & 4477.33 & 951.00 & 2279.33 & 7.3 \\
\hline 64 & 3.3 & 7 & 24 & 32 & 124 & 31 & 54 & 71.60 & 3200.33 & 2297.33 & 4820.00 & 903.00 & 2522.67 & 7.1 \\
\hline 65 & 2.6 & 6.4 & 23 & 34 & 123 & 23 & 46 & 64.87 & 2656.00 & 1756.67 & 3799.67 & 899.33 & 2043.00 & 7.4 \\
\hline 66 & 2.1 & 7.3 & 32 & 41 & 107 & 22 & 47 & 68.37 & 3053.67 & 2309.00 & 4522.00 & 841.00 & 2242.67 & 7.3 \\
\hline 67 & 2.2 & 6.8 & 34 & 39 & 107 & 22 & 44 & 65.30 & 3026.33 & 2165.00 & 4403.67 & 861.33 & 2038.67 & 7.4 \\
\hline
\end{tabular}

Contd..... 
Kumar S. et al. / J. Appl. \& Nat. Sci. 10 (2): 723 - 740 (2018)

\begin{tabular}{|c|c|c|c|c|c|c|c|c|c|c|c|c|c|c|}
\hline 68 & 2.4 & 6.8 & 25 & 35 & 120 & 24 & 47 & 57.97 & 3257.00 & 2129.33 & 3968.67 & 1127.67 & 1839.33 & 7.1 \\
\hline 69 & 2.4 & 6.7 & 27 & 31 & 122 & 23 & 48 & 65.13 & 2781.67 & 1825.33 & 3829.00 & 956.33 & 2003.67 & 6.8 \\
\hline 70 & 2.7 & 6.6 & 25 & 30 & 125 & 24 & 47 & 62.27 & 2887.67 & 1822.67 & 4306.00 & 1065.00 & 1483.33 & 6.9 \\
\hline 71 & 2.4 & 7.8 & 27 & 36 & 117 & 26 & 60 & 70.80 & 2445.00 & 1454.67 & 3555.33 & 1012.00 & 2592.67 & 7 \\
\hline 72 & 2.5 & 7.1 & 21 & 32 & 127 & 26 & 54 & 71.23 & 2757.00 & 1854.00 & 4094.67 & 899.67 & 2337.33 & 7.3 \\
\hline 73 & 3 & 6.2 & 18 & 25 & 137 & 27 & 49 & 72.20 & 2743.67 & 1797.00 & 4149.67 & 992.33 & 2266.33 & 7.3 \\
\hline 74 & 2.4 & 6.7 & 26 & 39 & 115 & 23 & 45 & 70.03 & 2227.67 & 1473.67 & 3822.33 & 754.00 & 2348.67 & 7.1 \\
\hline 75 & 2.7 & 7 & 25 & 32 & 123 & 26 & 53 & 70.90 & 2444.33 & 1494.33 & 3892.00 & 949.67 & 2397.67 & 7.4 \\
\hline 76 & 3.9 & 7.9 & 17 & 36 & 127 & 43 & 69 & 70.93 & 2651.00 & 1811.33 & 4404.67 & 839.67 & 2593.33 & 7.3 \\
\hline 77 & 3.6 & 6.4 & 18 & 32 & 130 & 31 & 52 & 65.27 & 3394.00 & 2371.33 & 4934.33 & 1042.67 & 2563.00 & 7.2 \\
\hline 78 & 3.7 & 6.5 & 18 & 29 & 133 & 36 & 58 & 71.80 & 2394.00 & 1512.00 & 3807.33 & 889.33 & 2325.67 & 7.3 \\
\hline 79 & 2.7 & 6.7 & 21 & 21 & 138 & 28 & 53 & 68.07 & 2560.67 & 1802.00 & 4078.00 & 888.33 & 2335.67 & 7.1 \\
\hline 80 & 3.4 & 6.6 & 18 & 24 & 138 & 31 & 57 & 72.47 & 2920.00 & 1987.33 & 3797.00 & 939.33 & 2391.00 & 7.1 \\
\hline C 518 & 1.3 & 6.2 & 56 & 28 & 96 & 10 & 38 & 68.67 & 2049.67 & 1227.67 & 2414.67 & 837.67 & 1292.33 & 7.9 \\
\hline PBW 343 & 1.4 & 5.9 & 43 & 30 & 107 & 12 & 37 & 67.37 & 2686.00 & 1830.00 & 3110.00 & 889.00 & 1285.67 & 7.7 \\
\hline & & & & & & & & ns & 603.25 & 555.14 & 1093.57 & 395.38 & 578.09 & \\
\hline
\end{tabular}

$\mathrm{MTi}=$ mixing time $(\mathrm{min}), \mathrm{DS}=$ Dough strength $(\mathrm{cm}), \mathrm{RDD}=$ rate of dough development $\left({ }^{\circ}\right), \mathrm{RDW}=\mathrm{Rate}$ of dough weakening $\left({ }^{\circ}\right)$, MTo $=$ Mixing tolerance $\left({ }^{\circ}\right)$, DDA $=$ Dough development area $\left(\mathrm{cm}^{2}\right)$, BS $=$ Baking strength $\left(\mathrm{cm}^{2}\right), \mathrm{PT}=$ Paste temperature $\left({ }^{\circ} \mathrm{C}\right), \mathrm{PV}=$ Peak Viscosity $(\mathrm{rpm}), \mathrm{HV}=$ Hold viscosity $(\mathrm{rpm}), \mathrm{FV}=$ Final Viscosity $(\mathrm{rpm}), \mathrm{Bd}=$ Breakdown $(\mathrm{rpm}), \mathrm{Sb}=$ Setback $(\mathrm{rpm}), \mathrm{CS}=$ Chapati score

Table 10. Correlation matrix of the starch pasting characteristics evaluated for cultivars and genetic stocks during first year.

\begin{tabular}{|c|c|c|c|c|c|c|c|c|}
\hline & $\begin{array}{l}\text { Paste tem- } \\
\text { perature }\end{array}$ & $\begin{array}{l}\text { Peak vis- } \\
\text { cosity }\end{array}$ & $\begin{array}{l}\text { Hold } \\
\text { cosity }\end{array}$ & vis- & $\begin{array}{l}\text { Final vis- } \\
\text { cosity }\end{array}$ & $\begin{array}{l}\text { Set- } \\
\text { back }\end{array}$ & $\begin{array}{l}\text { Break- } \\
\text { down }\end{array}$ & $\begin{array}{l}\text { Falling } \\
\text { number }\end{array}$ \\
\hline Peak viscosity & -0.10 & & & & & & & \\
\hline Hold viscosity & 0.03 & $0.95^{*}$ & & & & & & \\
\hline Final viscosity & 0.15 & $0.90^{*}$ & $0.95^{*}$ & & & & & \\
\hline Setback & $-0.35^{*}$ & $0.79^{*}$ & $0.57^{*}$ & & $0.48^{*}$ & & & \\
\hline Breakdown & $0.45^{*}$ & $0.46^{*}$ & $0.53^{*}$ & & $0.76^{*}$ & 0.10 & & \\
\hline Falling nmber & 0.12 & $0.69^{*}$ & $0.82^{*}$ & & $0.73^{*}$ & 0.21 & $0.25^{*}$ & \\
\hline Chapati Score & $-0.33^{*}$ & $0.26^{*}$ & 0.17 & & 0.18 & $0.36^{*}$ & 0.05 & $0.31^{*}$ \\
\hline
\end{tabular}

* Significant at $5 \%$ level

Table 11. Correlation matrix of the starch pasting characteristics evaluated for cultivars and genetic stocks during second year.

\begin{tabular}{llllllll}
\hline & $\begin{array}{l}\text { Paste tem- } \\
\text { perature }\end{array}$ & $\begin{array}{l}\text { Peak vis- } \\
\text { cosity }\end{array}$ & $\begin{array}{l}\text { Hold vis- } \\
\text { cosity }\end{array}$ & $\begin{array}{l}\text { Final vis- } \\
\text { cosity }\end{array}$ & Setback & $\begin{array}{l}\text { Break- } \\
\text { down }\end{array}$ & $\begin{array}{l}\text { Falling } \\
\text { number }\end{array}$ \\
\hline Peak viscosity & $-0.38^{*}$ & & & & & & \\
Hold viscosity & $0.30^{*}$ & $0.78^{*}$ & & & & & \\
Final viscosity & 0.16 & $0.68^{*}$ & $0.98^{*}$ & & & & \\
Setback & $-0.89^{*}$ & $0.47^{*}$ & -0.20 & $-0.28^{*}$ & & & \\
Breakdown & $-0.53^{*}$ & $0.70^{*}$ & $0.92^{*}$ & 0.1 & -0.10 & & \\
Falling nmber & $-0.45^{*}$ & $0.47^{*}$ & $0.62^{*}$ & $0.52^{*}$ & -0.08 & $0.78^{*}$ & 0.08 \\
Chapati Score & $-0.90^{*}$ & $-0.54^{*}$ & $-0.69^{*}$ & $-0.31^{*}$ & -0.09 & 0.21 & 0 \\
\hline
\end{tabular}

* Significant at $5 \%$ level

of $9.00 \mathrm{~cm}^{2}$ and $9.67 \mathrm{~cm}^{2}$ respectively. In this group only PBW 550 gave high value of 18.67 $\mathrm{cm}^{2}$. The genetic stocks on the other hand gave high values with $\mathrm{WH} 1003$ giving highest value of $27.33 \mathrm{~cm}^{2}$ for the season. K 0123, however, gave a low value of $12.67 \mathrm{~cm}^{2}$. The released varieties with known quality also gave low values of dough development area having a group average of $13.08 \mathrm{~cm}^{2}$. Intermediate range of values was observed for the tall wheats, which gave best chapati scores. The advanced lines PBW 534 and PBW 554 gave higher values whereas $\mathrm{HI} 1418$ and $\mathrm{HI}$ 1479 gave low values for dough development area. Overall examination of data for the two seasons showed that the tall varieties changed little over time for dough development area. In general the stronger wheats produce mixing curves with larger dough development area. Ideally the dough development area should be lower which corresponds with the lower energy requirements for developing satisfactory dough. This fact is of greater importance in case of varieties included for use in chapati making whereas mixing of dough is generally carried through manual kneading. The populations were found to be normally distributed for dough development area, with the population mean of ' $\mathrm{B}$ ' population being higher than other two populations. Most of the lines in the populations were observed to give higher values than the better parent in all the three recombinant populations. In population ' $A$ ' the dough development area values observed for the parents were $18 \mathrm{~cm}^{2}$ and $9 \mathrm{~cm}^{2}$ for C 273 and PBW 343 respectively. Only 1 genotype out of 70 was found to 
Kumar S. et al. / J. Appl. \& Nat. Sci. 10 (2): 723 - 740 (2018)

Table 12. Correlation matrix of the mixographic characteristics evaluated for cultivars and genetic stocks during first year.

\begin{tabular}{|c|c|c|c|c|c|c|c|}
\hline & $\begin{array}{l}\text { Mixing } \\
\text { time }\end{array}$ & $\begin{array}{l}\text { Dough } \\
\text { strength }\end{array}$ & $\begin{array}{l}\text { Rate of } \\
\text { dough de- } \\
\text { velopment }\end{array}$ & $\begin{array}{l}\text { Rate of } \\
\text { dough } \\
\text { weakening }\end{array}$ & $\begin{array}{l}\text { Mixing } \\
\text { tolerance } \\
\text { index }\end{array}$ & $\begin{array}{l}\text { Dough } \\
\text { develop- } \\
\text { ment area } \\
\end{array}$ & $\begin{array}{l}\text { Baking } \\
\text { strength }\end{array}$ \\
\hline $\begin{array}{l}\text { Dough } \\
\text { strength }\end{array}$ & 0.10 & & & & & & \\
\hline $\begin{array}{l}\text { Rate of dough } \\
\text { development }\end{array}$ & $-0.56^{*}$ & $0.58^{*}$ & & & & & \\
\hline $\begin{array}{l}\text { Rate of dough } \\
\text { weakening }\end{array}$ & $-0.49^{*}$ & $0.25^{*}$ & $0.40^{*}$ & & & & \\
\hline $\begin{array}{l}\text { Mixing toler- } \\
\text { ance index }\end{array}$ & $0.64^{*}$ & $-0.54^{*}$ & $-0.92^{*}$ & $-0.73^{*}$ & & & \\
\hline $\begin{array}{l}\text { Dough devel- } \\
\text { opment area }\end{array}$ & $0.93^{*}$ & $0.42^{*}$ & $-0.31^{*}$ & $-0.32^{*}$ & $0.37^{*}$ & & \\
\hline $\begin{array}{l}\text { Baking } \\
\text { strength }\end{array}$ & $0.50^{*}$ & $0.67^{*}$ & 0.06 & -0.16 & 0.03 & $0.71^{*}$ & \\
\hline Chapati Score & $-0.44^{*}$ & $-0.68^{*}$ & -0.20 & 0.16 & 0.08 & $-0.61^{*}$ & $-0.68^{*}$ \\
\hline
\end{tabular}

* Significant at $5 \%$ level

Table 13. Correlation matrix of the mixographic characteristics evaluated for cultivars and genetic stocks during second year.

\begin{tabular}{|c|c|c|c|c|c|c|c|}
\hline & $\begin{array}{l}\text { Mix- } \\
\text { ing } \\
\text { time }\end{array}$ & $\begin{array}{l}\text { Dough } \\
\text { strength }\end{array}$ & $\begin{array}{l}\text { Rate of } \\
\text { dough de- } \\
\text { velopment }\end{array}$ & $\begin{array}{l}\text { Rate of } \\
\text { dough } \\
\text { weakening }\end{array}$ & $\begin{array}{l}\text { Mixing } \\
\text { tolerance } \\
\text { index }\end{array}$ & $\begin{array}{l}\text { Dough } \\
\text { develop- } \\
\text { ment area }\end{array}$ & $\begin{array}{l}\text { Baking } \\
\text { strength }\end{array}$ \\
\hline Dough strength & $-0.37^{*}$ & & & & & & \\
\hline $\begin{array}{l}\text { Rate of dough } \\
\text { development }\end{array}$ & $-0.91^{*}$ & $0.58^{*}$ & & & & & \\
\hline $\begin{array}{l}\text { Rate of dough } \\
\text { weakening }\end{array}$ & $-0.59^{*}$ & $0.50 *$ & $0.57^{*}$ & & & & \\
\hline $\begin{array}{l}\text { Mixing tolerance } \\
\text { index }\end{array}$ & $0.85^{*}$ & $-0.61^{*}$ & $-0.89^{*}$ & $-0.88^{*}$ & & & \\
\hline $\begin{array}{l}\text { Dough develop- } \\
\text { ment area }\end{array}$ & $0.97^{*}$ & -0.19 & $-0.82^{*}$ & $-0.48^{*}$ & $0.74^{*}$ & & \\
\hline Baking strength & $0.82^{*}$ & 0.14 & $-0.58^{*}$ & $-0.37^{*}$ & $0.54^{*}$ & $0.79^{*}$ & \\
\hline Chapati score & -0.14 & 0.23 & $0.33^{*}$ & $0.28^{*}$ & $-0.34^{*}$ & -0.01 & -0.20 \\
\hline
\end{tabular}

\section{* Significant at $5 \%$ level}

have dough development area values to range between the parental values. 69 genotypes gave higher values than that of C 273 whereas no genotype was found to have value lower than that of PBW 343. In population 'B' the values of the parents, C 306 and PBW 534, observed were $11 \mathrm{~cm}^{2}$ and $22 \mathrm{~cm}^{2}$ respectively. Only 3 genotypes out of 70 were found to have values in the parental range whereas 67 genotypes gave values higher than that of PBW 534 and no genotype had values lower than that of $C$ 306. In population ' $C$ ' 3 genotypes out of 80 were observed to have values of dough development area in the parental range of $10 \mathrm{~cm}^{2}$ (C 518) and $12 \mathrm{~cm}^{2}$ (PBW 343). 74 genotypes had values higher than that of PBW 343 whereas only 3 genotypes were having values lower than that of C 518 .

Baking strength is the total area under the mixographic curve and determines the suitability of a wheat variety for its end use. Baking strength of the genotypes varied from $39.00 \mathrm{~cm}^{2}$ for PBW 502 to $51.67 \mathrm{~cm}^{2}$ for WH 1003 in first year. The genetic stocks showed a range of values for baking strength, with WH 1003 and WH $800\left(51.33 \mathrm{~cm}^{2}\right)$ giving high values where as $\mathrm{KYZ} \mathrm{K} 2 \mathrm{~K}-13$ gave a low value of $39.33 \mathrm{~cm}^{2}$. The advanced lines, however, gave high values whereas the tall wheats and the commercially grown varieties showed low to medium range of values for baking strength. Glupro was observed to have a high value of 59 $\mathrm{cm}^{2}$. In second year the baking strength was found to vary from $37.33 \mathrm{~cm}^{2}$ for PBW 502 to $53.33 \mathrm{~cm}^{2}$ for PBW 550. The genetic stocks gave high values, whereas the commercial wheat varieties such as PBW 343 and DBW 16 gave baking strength values of less than $40 \mathrm{~cm}^{2}$. The advanced lines PBW 534 and PBW 554 gave a high value of $51 \mathrm{~cm}^{2}$, whereas, $\mathrm{HI} 1418$ and $\mathrm{HI} 1479$ gave a low value of $41.67 \mathrm{~cm}^{2}$. The released varieties with known quality and the tall wheats were once again found to have low to medium values of baking strength in this season also. The variation 
Kumar S. et al. / J. Appl. \& Nat. Sci. 10 (2): 723 - 740 (2018)

Table 14. Correlation coefficients of the mixographic and starch pasting characteristics with chapati score for recombinant populations

\begin{tabular}{llllllll}
\hline Starch pasting characters & \multicolumn{3}{l}{ Correlation coefficient } & Mixographic characters & \multicolumn{2}{c}{ Correlation coefficient } \\
\hline & A & B & C & & A & B & C \\
\hline Pasting temperature & 0.16 & -0.02 & 0.12 & Mixing time & $-0.31^{*}$ & $-0.45^{*}$ & -0.17 \\
Peak viscosity & $-0.31^{*}$ & 0.10 & -0.06 & Strength & 0.05 & 0.03 & -0.17 \\
Hold viscosity & -0.22 & -0.11 & -0.09 & Rate of dough development & $0.32^{*}$ & $0.40^{*}$ & $0.34^{*}$ \\
Final viscosity & $-0.38^{*}$ & -0.13 & $-0.24^{*}$ & Rate of dough weakening & 0.00 & $0.28^{*}$ & -0.04 \\
Breakdown & $-0.27^{*}$ & 0.14 & 0.05 & Mixing tolerance & -0.17 & $-0.39^{*}$ & -0.21 \\
Setback & $-0.44^{*}$ & -0.16 & -0.33 & Dough development area & -0.23 & -0.06 & $-0.23^{*}$ \\
Falling number & -0.01 & 0.06 & -0.03 & Baking strength & -0.07 & 0.22 & $-0.23^{*}$ \\
\hline
\end{tabular}

* Significant at $5 \%$ level

for the trait over the period of study was not much and the characteristic seems to be quite stable therefore it can be successfully utilized in screening of breeding materials. The baking strength of the lines in the recombinant populations was found to be normally distributed in all the three cases. Baking strength values higher than the better parent were recorded in most of the genotypes within population ' $\mathrm{B}$ ' giving higher population mean than other two populations. In population ' $A$ ' the values of baking strength of the parents were observed to be $49 \mathrm{~cm}^{2}$ and $36 \mathrm{~cm}^{2}$ for C 273 and PBW 343 respectively. 17 genotypes out of 70 gave values in this parental range, whereas 53 genotypes gave values higher than that of C 273 and no genotypes was found to have value lower than that of PBW 343. In population ' $\mathrm{B}$ ' the parental values of baking strength were observed to be $42 \mathrm{~cm}^{2}$ and $50 \mathrm{~cm}^{2}$ for C 306 and PBW 534 respectively. 3 genotypes out of 70 were found to range in between the parental values whereas 65 genotypes gave values of baking strength higher than that of PBW 534 and only 2 genotypes were found to have values lower than that of $C$ 306. In population ' $C$ ' the parental range was observed to be narrow and the values of baking strength observed for C 518 and PBW 343 were $38 \mathrm{~cm}^{2}$ and $37 \mathrm{~cm}^{2}$ respectively. All the 80 genotypes in the population were found to have baking strength values higher than that of $C 518$.

Rheological studies are being utilised extensively for the evaluation of flour quality (Vizitiu et al 2012). Ahmed et al. (2015) studied physicochemical and rheological properties of soft wheat flours obtained from different wheat varieties grown in Pakistan, Ukraine and India. The rheological behaviour of Indian wheat flour showed high water absorption, high dough stability and less degree of softening. Our results are in line with the reports from literature.

Genetic variation for starch pasting characteristics: Starch pasting characteristics, studied using Rapid Visco ${ }^{\mathrm{TM}}$ Analyser (RVA), include different parameters used to understand the viscoelastic properties of starch granules when subjected to high temperatures and mechanical shear. The pasting temperature provides an indication of the minimum temperature required to cook a giv- en sample. Peak viscosity indicates the waterbinding capacity of the starch whereas final viscosity depicts the ability of starch to form a viscous paste after cooking and cooling. The hold viscosity indicates the ability of a sample to withstand the heating and shear stress. The higher peak and final viscosity values indicate the higher water holding capacity of starch which has a significant role in the baking quality. Breakdown and setback define the quality of the starch. The genotypes showed significant genotypic differences for all starch pasting characteristics studied during both seasons (Table $3 \mathrm{a}$ and b). The mean performance of genotypes for various starch pasting characteristics is given in table 2 and 3 . The starch pasting characteristics were also found to have significant genotypic differences in all the three populations (Table $6 a, b$ and $c$ ). Whereas the mean performance of the genotypes for starch pasting characteristics is given respectively in table 7 , table 8 and 8 for population ' $A$ ', 'B' and ' $C$ '.

The pasting temperature for the wheat starch was observed to vary between $67.07^{\circ}$ for PBW 550 and $69.90^{\circ}$ for PBW 534 in first year. The tall wheats and the advanced lines recorded higher pasting temperature in comparison to genetic stocks and commercial wheats. In second year the pasting temperature showed more variation with the values ranging between $68.57^{\circ}$ for $8 \mathrm{~A}$ and $71.23^{\circ}$ for PBW 502. The genetic stocks, the commercial varieties and the advanced lines gave higher values. The tall wheats and the released varieties with known quality recorded values on lower side. The pasting temperature was found to show a lot of variation within and between the populations. The populations ' $A$ ' and ' $C$ ' were somewhat normally distributed and slightly skewed towards lower side. These populations gave non overlapping means for pasting temperature, whereas population ' $B$ ' was found to be skewed towards both the extremes. In population ' $A$ ' the values of pasting temperature obtained for the parents are $69.53^{\circ \mathrm{C}}$ and $71.07^{\circ \mathrm{C}}$ for C 273 and PBW 343 respectively. 4 genotypes out of 70 gave values in this parental range whereas 66 genotypes gave values lower than that of C 273 and no genotypes with a value more than that of PBW 343 was obtained. In population 'B' 12 geno- 
types out of 70 gave values in the parental range of $68.47^{\circ \mathrm{C}}$ (C 306) and 69.90 ${ }^{\circ \mathrm{C}}$ (PBW 534). 13 genotypes gave values less than that of $C 306$ whereas 45 genotypes were found to have pasting temperature values of more than that of PBW 534. In population ' $C$ ' the parents $C 518$ and PBW 343 gave pasting temperature values of $68.67^{\circ \mathrm{C}}$ and $67.37^{\circ \mathrm{C}}$ respectively. Only 3 genotypes out of 80 gave values in the parental range, whereas 46 genotypes were observed to have values higher than that of C 518 and 31 genotypes gave values lower than that of PBW 343.

The values of peak viscosity observed in first year varied from $1609.67 \mathrm{cp}$ for WH 423 to $3580.00 \mathrm{cp}$ for PBW 534. Low values were observed for all the tall wheats except $C 591$ which gave a value of $3021.33 \mathrm{cp}$. The genetic stocks on the other hand gave high values with WH 595 (3455.00 cp), WH 712 (3317.33 cp), WH 800 (3172.00 cp), WH 1003 (3266.67 cp) and HD 2793 (3042.33 cp) all recording values above $3000 \mathrm{cp}$. However, low values of $1609.67 \mathrm{cp}$ (WH 423) and $2194.00 \mathrm{cp}$ (KYZ K2K-13) were also recorded in this group. The commercial varieties and the advanced lines gave medium to high values of the peak viscosity in this season. In second year the observed values of peak viscosity ranged between $2623.00 \mathrm{cp}$ for $\mathrm{HI} 1418$ and $3800.00 \mathrm{cp}$ for $\mathrm{WH} 1003$. The genetic stocks showed high values in this season and the tall wheats gave values on lower side for peak viscosity. In tall wheats group 9D (3508.67 $\mathrm{cp})$ and C 591 (3493.67 cp), whereas in released varieties with known quality group Lok 1 (3583.67 $\mathrm{cp})$ and PBW 175 (3662.00 cp) gave higher values of peak viscosity. All the advanced lines, barring HI 1418 which gave $2623.00 \mathrm{cp}$, gave high values as was the case with commercial wheat varieties. However DBW 16 gave a value on lower side $(2973.00 \mathrm{cp})$. The populations were found to have a wide range of variation as far as peak viscosity is concerned. The parental extremes as well as transgressive segregants on both sides were obtained in all the three populations. The peak viscosity of the parents of population ' $A$ ' was observed to be $3190.00 \mathrm{cp}$ and $3399.00 \mathrm{cp}$ for $\mathrm{C}$ 273 and PBW 343 respectively. 16 genotypes out of 70 were found to have peak viscosity in this parental range, whereas 31 genotypes gave values higher to that of PBW 343 and 23 genotypes gave values lower to that of $C 273$. In population 'B' 45 genotypes out of 70 were found to have peak viscosity values in the parental range of $2588.00 \mathrm{cp} \mathrm{(C} \mathrm{306)} \mathrm{and} 3580.00 \mathrm{cp}$ (PBW 534). 18 genotypes gave values higher to that of PBW 534 and 7 genotypes gave values lower than that of C 306. In population ' $C$ ' the parents C 518 and PBW 343 were observed to have peak viscosity values of $20.49 .67 \mathrm{cp}$ and $2686.00 \mathrm{cp}$ respectively. 49 genotypes out of 80 gave values in this parental range, whereas 26 genotypes were found to have values higher than that of PBW 343 and only 5 genotypes gave values lower than that of $C 518$. The value of hold viscosity varied from $919.67 \mathrm{cp}$ for WH 423 to $2528.33 \mathrm{cp}$ for PBW 534 in first year. The tall wheats gave medium range of values with $C 518$ giving a value of $1227.67 \mathrm{cp}$. The genetic stocks gave values ranging from low for KYZ K2K-13 (1284.00 cp) to high for WH 595 (2251.33 cp). The commercial varieties and the advanced lines showed medium values with only PBW 534 giving high value for hold viscosity. The values of hold viscosity ranged between 1891.33 cp for HI 1418 and $2941.67 \mathrm{cp}$ for WH 1003 in second year. The genetic stocks gave higher values with $\mathrm{WH} 1003$ giving the highest value in the season. The commercial wheats also gave high values of hold viscosity; PBW 533 however, gave a medium value of $2234.33 \mathrm{cp}$. The tall wheats gave low to medium values except 9D (2680.67 $\mathrm{cp})$ which gave a high value. The advanced lines (except HI 1418) gave medium values, whereas released varieties with known quality PBW 175 (2738.00 cp) and LOK 1 (2612.67 cp) gave high values. PBW 226, however, gave a low value of $2006.33 \mathrm{cp}$ hold viscosity. All the three recombinant populations exhibited normal distribution for variation in hold viscosity. In population 'A' a large number of transgressive segregants were found to be on lower side where as their number was more on higher side in population ' $C$ '. In population ' $B$ ' most of the variation for this trait was found to be lying in between the parental range with a few individuals being outside the range on both higher and lower sides. The parents of population ' $A$ ' $C$ 273 and PBW 343 gave hold viscosity values of $2388.67 \mathrm{cp}$ and $2828.67 \mathrm{cp}$ respectively. 19 genotypes out of 70 gave values in this parental range, whereas 49 were observed to have lower value of hold viscosity than that of C 273. Only 2 genotypes were found to have values higher than that of PBW 343. In population 'B' the hold viscosity values of the parents were observed to be $1679.67 \mathrm{cp}$ and $2528.33 \mathrm{cp}$ for C 306 and PBW 534 respectively. 50 genotypes out of 70 gave values in this parental range with only 4 genotypes having higher values than that of PBW 534. 16 genotypes were observed to give hold viscosity values lower than that of $C 306$. In population ' $C$ ' the parental values for hold viscosity were observed to be $1227.67 \mathrm{cp}$ and $1830.00 \mathrm{cp}$ for C 518 and PBW 343 respectively. 40 genotypes out of 80 were observed to fall in this range whereas 34 gave higher values than PBW 343 and 6 genotypes gave values lower to that of $C 518$.

The final viscosity of the set of genotypes in first year ranged between $1827.67 \mathrm{cp}$ for WH423 and $4154.00 \mathrm{cp}$ for PBW 534. The tall wheats recorded medium range of values except $C 518$ which gave a low value of $2414.67 \mathrm{cp}$. The advanced lines PBW 554 (2819.67 cp) and PBW 531 
(2553.33 cp) gave medium values in comparison to PBW 534 which gave highest value in the season. The commercial varieties gave high values except PBW 502 which gave a low value of $2560.67 \mathrm{cp}$ for final viscosity. The genetic stocks showed a range of values from $1827.67 \mathrm{cp}(\mathrm{WH}$ 423 ) to $3525.00 \mathrm{cp}$ (HD 2793). The values of final viscosity in second year, ranged from $3351.00 \mathrm{cp}$ for $\mathrm{HI} 1418$ to $4658.33 \mathrm{cp}$ for $\mathrm{K} 0123$. All the genetic stocks and the commercial wheat varieties except PBW 533 (3579.33 cp) gave high values of final viscosity whereas the tall wheats gave lower values in comparison. Low values were observed for PBW 226 (3408.67 cp) and WG 357 (3513.67 $\mathrm{cp})$. The advanced lines also gave high values with an exception of $\mathrm{HI}$ 1418. On the whole the final viscosity values during second year were much higher showing thereby that this character is affected by the environment to a great extent. A wide range of variation was observed for final viscosity in all the populations. The variation was found to be normally distributed in all the three cases. In populations ' $A$ ' and ' $B$ ' more number of lines were observed above the better parent where as in population ' $C$ ' almost all the variation was found to be on higher side of the better parent. The final viscosity values of the parents of population ' $A$ ' were observed to be $3914.67 \mathrm{cp}$ and $4396.67 \mathrm{cp}$ for C 273 and PBW 343 respectively. 37 genotypes out of 70 were observed to have final viscosity values higher than that of PBW 343 and 15 genotypes gave values lower than that of $C 273$ whereas 18 genotypes fell in the parental range. In population ' $\mathrm{B}$ ' 18 genotypes out of 70 fell in the parental range of $3132.00 \mathrm{cp}$ (C 306) and $4154.00 \mathrm{cp}$ (PBW 534). 50 genotypes were having a final viscosity higher than that of PBW 534 whereas only 2 genotypes were found inferior to $C$ 306. In population ' $C$ ' the parental values of final viscosity for C 518 and PBW 343 were observed to be $2414.67 \mathrm{cp}$ and $3110.00 \mathrm{cp}$ respectively. 72 genotypes out of 80 gave values higher than that of PBW 343 and 3 genotypes were found to have final viscosity lower than that of $C 518.5$ genotypes gave values in the parental range.

Breakdown values ranged from $844.00 \mathrm{cp}$ for PBW 502 to $1606.00 \mathrm{cp}$ for PBW 534 in first year. High values of breakdown were observed for all the tall wheats and the commercial wheat varieties except PBW 502 which gave lowest value in the season. The advanced lines also gave low to medium values with PBW 534 being an exception. The genetic stocks gave higher values with only WH 423 and KYZ K2K 13 showing low values of $954.33 \mathrm{cp}$ and $1078.00 \mathrm{cp}$ respectively. In second year the values of breakdown were found to range from $1126.33 \mathrm{cp}$ for $\mathrm{HI} 1418$ to $1976.00 \mathrm{cp}$ for K 0123 . The tall wheats and the genetic stocks gave high values in this season, whereas the commer- cial wheat varieties and the advanced lines gave low values of breakdown. Medium to high values of breakdown were however observed for the released varieties with known quality. The breakdown viscosity of the individuals in the recombinant populations was observed to be normally distributed and the individuals excelling above the better parent were found in large numbers. Most of the transgressive segregation was on higher side of the better parent. In population 'A' the values of breakdown viscosity observed for the parents were $1526.00 \mathrm{cp}$ and $1568.00 \mathrm{cp}$ for C 273 and PBW 343 respectively. Only 2 genotypes out of 70 in this population were observed to have breakdown viscosity in this parental range. 65 genotypes gave higher values than that of PBW 343 and 3 genotypes were found to have values below that of $C 273$. In population 'B' 66 genotypes out of 70 were observed to have breakdown viscosity more than that of PBW 534 (1606.00 cp) and only 1 genotypes gave values less than that of $C 306$, whereas 3 genotypes gave values in the parental range. In population ' $C$ ' the parents $C$ 518 and PBW 343 were observed to have breakdown viscosity of $1292.33 \mathrm{cp}$ and $1285.67 \mathrm{cp}$ respectively. 77 genotypes out of 80 gave higher values of breakdown than that of C 518 and 3 genotypes gave values below the value of PBW 343. No genotype was however found to fall in the parental range.

Setback is the difference between hold viscosity and the final viscosity. It determines the viscosity of the wheat flour paste on cooling and the final water holding capacity at a specified viscosity level. The values for setback ranged from $720.67 \mathrm{cp}$ for WH 423 to $1415.67 \mathrm{cp}$ for PBW 509 in first year. The tall wheats $C 306$ and $C 518$ were found to have lower values of $953.67 \mathrm{cp}$ and $837.67 \mathrm{cp}$ respectively, whereas C $273(1030.33 \mathrm{cp})$ and C 591 (1056.67 cp) were found to have mediumhigh values of setback viscosity. Similarly the commercial wheat varieties PBW 343 (861.67 cp) and PBW 502 (766.33 cp) gave low values, whereas PBW 550 (1093.00 cp) and PBW 509 (1415.67 cp) gave medium and high values respectively. The advanced lines also gave medium to high values for setback, whereas the genetic stocks gave variable range of values in this season. The winter wheat, Glupro, however gave lowest value of $671.67 \mathrm{cp}$. In second year the values of setback viscosity incase of tall wheats were observed on same lines as in last season. C 306 (668.67 cp) and C 518 (661.00 cp) gave relatively lower values in comparison to C 273 (801.33 cp) and C 591 (938.67 cp). In commercial wheat varieties group PBW 343 and PBW 502 gave low values again in this season. DBW 16 in this group however gave lowest value of $340.00 \mathrm{cp}$. The highest value of setback in this season was observed to be $1019.67 \mathrm{cp}$ for PBW 534 from ad- 
vanced lines group. The released varieties with known quality gave high values of setback, whereas the genetic stocks gave medium to high values except HD 2793 which gave a lower value of $526.67 \mathrm{cp}$. The genetic variation for setback viscosity in case of recombinant populations was found to be normally distributed in all the three cases. In all the populations the transgressive segregants were observed in large numbers on higher side with few showing values on lower side of the parental range. In population ' $A$ ' 69 genotypes out of 70 were observed to have setback values higher than that of $C 273(801.33 \mathrm{cp})$ and 1 genotype gave values in the parental range. However no genotypes with setback value lower than that of PBW 343 was observed in the population. In ' $B$ ' population the parental values of setback observed were $953.67 \mathrm{cp}$ and $1019.67 \mathrm{cp}$ for C 306 and PBW 534 respectively. 19 genotypes out 70 were found to have values of setback viscosity in the parental range whereas 36 genotypes gave values higher than that of PBW 534 and 15 genotypes gave values lower than that of $C 306$. In population ' $C$ ' the parents were observed to have the setback values of $837.67 \mathrm{cp}$ and $889.00 \mathrm{cp}$ for C 518 and PBW 343 respectively. 9 genotypes out of 80 were found to have values in this parental range whereas 66 genotypes gave higher values of setback than that of PBW 343 and 5 genotypes gave values lower than that of C 518 .

Correlation of different traits with chapati score: Association of traits studied with chapati score in set of cultivars and genetic stocks for two years as revealed by genotypic correlation coefficients is given in table 10 and 11 for starch pasting and in table 12 and 13 for mixographic characteristics. Starch pasting characteristics showed mild negative correlation with chapati quality, which is again contrasting, to the requirements of bread making. The correlations were not consistent over years possibly due to environmental factor and due to change in the constitution of the set. Similarly mixographic traits showed negative association chapati making quality. Thus unlike bread making strong dough is not suitable for chapati purposes or we can say that the genotypes chosen were having low mixing time $(<2 \mathrm{~min})$ except for 'Glupro' in first year (3.10 min). This trend is reinforced by mild negative correlation observed for baking strength as well. Other mixographic traits did not seem to have clear implications for chapati quality. In general superior chapati quality wheats scored low for almost all the mixographic characteristics thus negative correlation as observed in one or the other season was expected. Consistent trends were however not observed possibly due to change in set constituents and differential environment prevailing in two seasons. Thus, the other set of quality parameters associated with bread making were seemed to be of no consequence for chapati making quality. A positive correlation trend has been reported earlier (Gupta et al 1993; Zhang et al 2008; Singh et al 2011).

The correlations which prevail in the populations carry much greater weight as these have persisted over several rounds of recombination and are likely to reflect under lying causes of superior chapati quality. As various components of chapati quality would be disassembled, the relative levels of correlations for individual traits would be uncovered. The present study in this regard represents an important advance as most of previous correlation studies were based on set of cultivars. The availability of single year data in case of populations is to some extent off set by the presence of three populations, namely A, B and C. Valuable correlation trends which extend across the three populations are summarized in table 14. Among the starch pasting characteristics, final viscosity and setback are consistently negatively associated with the chapati making quality. In case of the mixographic traits, mixing tolerance index is negatively associated whereas rate of dough development has consistent positive correlation with chapati quality.

\section{Conclusion}

The above trends have become visible due to availability of three parallel experiments on three recombinant populations. The bias in the correlation landscape generated by the set of cultivars and genetic stocks stands corrected in the aspects that two starch pasting and two mixographic traits have been identified to be associated with superior chapati quality. Chapati-making properties of flours from different wheat varieties is generally influenced with starch content and rheological properties of gluten. This study is one of its kind as it tries to explain the genetic basis of these traits based on recombinant populations. This work can further is used in wheat grain industry for producing wheat flour with specific characteristics as are desired for chapati quality.

\section{REFERENCES}

Anonymous. (2016). Progress Report of the All India Coordinated Wheat and Barley Improvement Project 2015-16, Vol. I, Crop Improvement. Eds: Vinod Tiwari, R Chatrath, G Singh, R Tiwari, BS Tyagi, Raj Kumar, SK Singh, Satish Kumar, CN Mishra, K Venkatesh, Mamrutha HM, Vikas Gupta, Gopalareddy, Ajay Verma, Indu Sharma, RK Gupta and GP Singh. Indian Institute of Wheat and Barley Research, Karnal, India. pp. 258.

Ahmed, R., Ali, R., Khan, M.S., Sayeed, S.A., Saeed, J. and Yousufi, F. (2015). Effect of proteases and carbohydarse on dough Rheology and End quality of cookie. American J. Food Sci. Nutri. Res., 2(2): 62-66

Austin, A. and Hanslas, V.K. (1983). Quality characteristics of Indian wheat cultivars. Wheat Project Directorate, IARI, New Delhi.

Blazek, J. and Copeland, L. (2008). Pasting and swell- 
ing properties of wheat flour and starch in relation to amylose content. Carbohydr Polym, 71: 380-387.

Das, B.K., Sharma, A., Marathe, S.A., Rao, V.S. and Bhagwat, S.G. (2006). Evaluation of bread and chapati making quality of wheat selections and parents differing in HMW subunits of glutenin. J. Food Sci. Technol., 43: 69-72.

Gupta, R.B., Khan, K. and Macritchie, F. (1993). Biochemical basis of flour properties in bread wheats. 1. Effects of variation in the quantity and size distribution of polymeric protein. J. Cereal Sci, 18: 23-44.

Hemalatha, M.S., Manu, B.T., Bhagwat, S.G., Leelavathi, K. and Rao, U.J.S.P. (2006). Protein characteristics and peroxidase activities of different Indian wheat varieties and their relationship to chapatimaking quality. European Food Res. Technol., 225: 463-471.

Hemalatha, M., Manohar, R.S., Salimath, P.S. and Rao, U.J.S.P. (2013). Effect of Added Arabinoxylans Isolated from Good and Poor Chapati Making Wheat Varieties on Rheological Properties of Dough and Chapati Making Quality. Food and Nutrition Sciences, 4: 884-892.

Hung, P.V., Yamamori, M. and Morita, N. (2005). Formation of enzyme resistant starch in bread as affected by high-amylose wheat flour substitutions. Cereal Chem, 82: 690-694.

Kumar, S., Sohu, V.S. and Bains, N.S. (2018). Agronomic performance of Indian wheat varieties and genetic stocks known for outstanding chapati quality characteristics. J. Appl. Natrl. Sci., 10(1): in press.

Morita, N., Maeda, T., Hung, P.V., Watanabe, M., Handoyo, T. and Yamamori. M. (2003). Textural properties and microscope observation of noodles made from various novel wheat flours. In: Proceedings of the $53^{\text {rd }}$ Australian Cereal Chemistry conference (pp. 153-156).

Rao-Haridas, P., Leelvathi, K. and Shurpalekar, S.R. (1989). Effect of damaged starch on the chapati making quality of whole wheat flour. Cereal Chem., 66: 329-333.

Sasaki, T., Yasui, T. and Kohyama, K. (2008). Influence of starch and gluten characteristics on rheological properties of wheat flour gels at small and large deformation. Cereal Chem., 85: 329-334.

Saxena, D.C., Rao, U.J.S.P. and Rao, P.H. (1997). Indian wheat cultivars: correlation between quality of gluten proteins, rheological characteristics of dough and tandoori roti quality. J. Sci. Food Agric., 74:265-272

Seib, P.A. (2000). Reduced-amylose wheats and Asian noodles. Cereal Foods World, 45: 504-512.

Sinha, A.C. and Singh, H.P. (1974). Studies on the farinographic and related characteristics of improved commercial varieties of Indian wheats. Bull. Grain. Tech., 12: 127-131.

Singh, S., Singh, N. and MacRitchie, F. (2011). Relationship of polymeric proteins with pasting, gel dynamic- and dough empirical-rheology in different Indian wheat varieties. Food Hydrocoll., 25: 19-24.

Vizitiu, D., Ognean, M. and Danci, I. (2012). Rheological evaluation of some laboratory mills. Bulletin of University of Agricultural Sciences and Veterinary Medicine ClujNapoca. Animal Sci. Biotechnol., 69(2):440-446

Zhang, P., He, Z., Zhang, Y., Xia, X., Chen, D. and Zhang, Y. (2008). Association between \% SDS unextractable polymeric protein (\%UPP) and endues quality in Chinese bread wheat cultivars. Cereal Chem., 85: 696-700. 